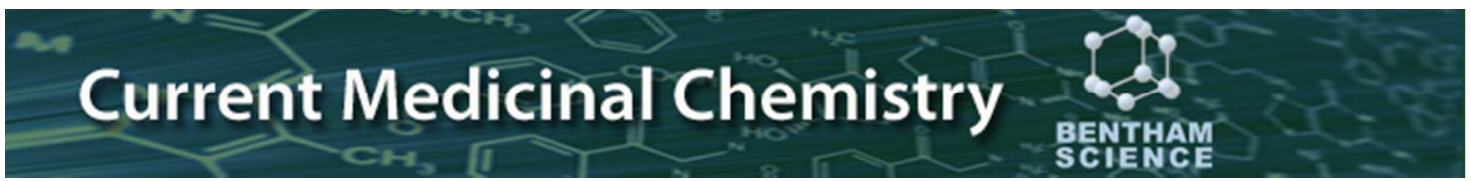

\title{
Niemann-Pick C1-Like 1 (NPC1L1) inhibition and cardiovascular diseases
}

\begin{tabular}{|r|l|}
\hline Journal: & Current Medicinal Chemistry \\
\hline Manuscript ID & CMC-2015-0219.R1 \\
\hline Danuscript Type: & Review \\
\hline Complete List of Authors: & $\begin{array}{l}\text { Pirillo, Angela; Centro SIS studio aterosclerosi } \\
\text { Catapano, Alberico } \\
\text { Norata, Giuseppe; Universita degli Studi di Milano }\end{array}$ \\
\hline Keywords: & $\begin{array}{l}\text { NPC1L1, cholesterol, cholesterol absorption, ezetimibe, LDL-C, } \\
\text { cardiovascular disease }\end{array}$ \\
\hline \multicolumn{2}{|l}{} \\
\hline
\end{tabular}

SCHOLARONE $^{\text {Ix }}$

Manuscripts 


\title{
Niemann-Pick C1-Like 1 (NPC1L1) inhibition and cardiovascular diseases
}

\author{
Pirillo $A^{1,2}$, Catapano $A L^{2,3}$, Norata $G^{1,3}$ \\ ${ }^{1}$ Center for the Study of Atherosclerosis, Bassini Hospital, Cinisello Balsamo, Italy \\ ${ }^{2}$ IRCCS Multimedica, Milan, Italy \\ ${ }^{3}$ Department of Pharmacological and Biomolecular Sciences. Università degli Studi \\ di Milano, Milan, Italy
}

\section{Address correspondence to:}

\section{Professor Alberico Luigi Catapano}

Department of Pharmacological and Biomolecular Sciences - Università degli Studi di Milano, Via Balzaretti 9, 20133 Milan, Italy

Alberico.Catapano@unimi.it 


\begin{abstract}
Circulating levels of cholesterol derive from either endogenous production or intestinal absorption of dietary and biliary cholesterol. Niemann-Pick C1-Like 1 (NPC1L1) is a transmembrane protein that plays a key role in the intestinal absorption of cholesterol by facilitating its uptake through vesicular endocytosis. NPC1L1 is the molecular target of ezetimibe which binds its extracellular loop and inhibits sterol absorption without affecting the absorption of other molecules. Ezetimibe significantly reduces plasma levels of total and low density lipoprotein cholesterol (LDL-C) as monotherapy or when added to statins, the association with a low dose of statin is of particular interest for patients experiencing statin-related side effects. The recent results of the IMPROVE-IT study, which evaluated the cardiovascular effect of ezetimibe added to simvastatin therapy in subjects who had had an acute coronary syndrome and with LDL-C levels within the recommended range, showed that a further LDL-C lowering reduced the incidence of cardiovascular events. To date, ezetimibe represents the only inhibitor of NPC1L1 available for clinical use, however, novel amino-ß-lactam ezetimibe derivatives have been synthesized and their efficacy to inhibit NPC1L1 protein and decrease plasma cholesterol levels is under evaluation.
\end{abstract}

Keywords: NPC1L1; cholesterol; cholesterol absorption; ezetimibe; LDL-C; cardiovascular disease 


\section{Introduction}

Niemann-Pick C1L1 (NPC1L1) protein plays a central role in the intestinal absorption of cholesterol and is a key determinant of plasma cholesterol levels ${ }^{1,2}$. In humans, NPC1L1 is present also in the liver, where it prevents excessive loss of biliary cholesterol $^{3}$.

While NPC1L1 overexpression increases cholesterol uptake in cells ${ }^{4}$ NPC1L1 knockout mice were protected against diet-induced hypercholesterolemia, as a consequence of the defective intestinal uptake of cholesterol ${ }^{5}$. In addition, naturally occurring loss of function mutations of NPC1L1 are associated with lower LDL-C levels and a reduced risk of coronary heart disease ${ }^{6}$. The observation that ezetimibe decreases intestinal cholesterol absorption via NPC1L1 inhibition, thus resulting in a reduction of plasma LDL-C levels by about $20 \%$ in monotherapy ${ }^{7}$, paved the road for a novel complementary approach for the treatment of hypercholesterolemia aimed at controlling endogenous cholesterol synthesis in the liver (statins) as well as dietary cholesterol absorption (ezetimibe).

Adding ezetimibe to established statin therapy results in a further incremental LDLC lowering of $15 \%-20 \%{ }^{8}$; the recent results of the IMPROVE-IT trial showed that ezetimibe, given in combination with simvastatin, reduced the combined cardiovascular outcome compared with simvastatin alone in acute coronary syndrome patients as a result of the additional LDL-C lowering obtained ${ }^{9}$. The aim of this review is to discuss the biological consequences of NPC1L1 inhibition on cholesterol homeostasis and the key aspects to be considered when designing novel ezetimibe analogs as potential cholesterol absorption inhibitors. 


\section{Biology of NPC1L1}

\section{Cholesterol homeostasis}

Cholesterol plays a key role in cell biology, as it is a main constituent of cell membranes, and in the body, as it is required for the formation of bile salts and is the precursor of steroid hormones and vitamin D. Due to its importance, there are several cellular and systemic mechanisms able to tightly regulate the abundance of cholesterol, including intestinal absorption, endogenous biosynthesis, reverse cholesterol transport and biliary/intestinal excretion. Elevated plasma cholesterol levels represent a risk factor for atherosclerosis and cardiovascular disease.

Intestinal cholesterol absorption is a complex multistep process regulated by multiple genes; among them, NPC1L1, which is involved in cholesterol uptake ${ }^{2}$, and ATPbinding cassette transporters ABCG5 and ABCG8, that function as heterodimer and promote cholesterol efflux into the intestinal lumen for excretion ${ }^{10}$. Defects in the ABCG5/ABCG8 system are linked to sitosterolemia, a condition characterized by high plasma levels of dietary sterols and premature coronary heart disease ${ }^{10}$.

\section{Expression, regulation and tissue distribution of NPC1L1}

NPC1L1 is a protein of 1,332 amino acids that plays a key role in the absorption of cholesterol; a truncated transcript has also been described, although its biological relevance is still not defined ${ }^{11,12}$. NPC1L1 is a homolog of Niemann-Pick C1 (NPC1) protein which plays a key role in chaperoning lysosomal cholesterol and, when mutated, causes Niemann-Pick disease type 1, a severe disease characterized by the accumulation of cholesterol and glycolipids in lysosomes ${ }^{13}$. NPC1L1 is a plasma membrane protein containing 13 putative transmembrane domains, several $\mathrm{N}$-linked 
glycosylation sites in the extracellular loops of the protein and a sterol-sensing domain $(\mathrm{SSD}){ }^{12,14,15}$ (Figure 1 ). The SSD is a region of 180 amino acids that forms five membrane-spanning helices with short intervening loops; this region is conserved in several other proteins playing a critical role in cholesterol homeostasis ${ }^{16,17}$. The extracellular N-terminal domain of NPC1L1, that in the absence of cholesterol is in a closed conformation, directly binds cholesterol, and this interaction is essential for NPC1L1-mediated cellular cholesterol uptake ${ }^{18,19}$ (Figure 1).

The cellular localization of NPC1L1 is strictly related to cholesterol content: when cells are enriched in cholesterol, NPC1L1 localizes in the endocytic recycling compartment; following cholesterol depletion it translocates to an apical-like subdomain at the cell surface, thus facilitating free cholesterol uptake 20,21 . Also NPC1L1 expression is tightly regulated by cellular cholesterol content and depends on several transcription factors, including SREBP-2, LXR $\alpha$, HNF4 $\alpha$ and PPARs ${ }^{22-26}$. Mice fed a high cholesterol diet have very low levels of intestinal NPC1L1 mRNA ${ }^{27}$ associated to reduced expression of $\mathrm{HNF} 4 \alpha$ and SREBP-2 26 , 28; on the contrary, cholesterol deprivation significantly raises NPC1L1 mRNA levels in both intestine and liver, while increasing SREBP-2 mRNA expression ${ }^{28}$. Recently, the nuclear receptor liver receptor homolog-1 (LRH-1) has been shown to affect hepatic expression of NPC1L1, likely through a synergistic transcriptional activation in combination with SREBP- $2^{29}$.

In addition to cholesterol, several other stimuli may modulate the expression of NPC1L1. As example, in mice, cholecystokinin, a peptide hormone responsible for the release of digestive enzymes and bile into the intestinal lumen, is known to raise plasma cholesterol levels by increasing cell-surface associated NPC1L1 in intestinal cells $^{30,31}$. In vitro, colecystokinin induces the activation of PI3K-Akt pathway that in turn facilitates the physical interaction of NPC1L1 with Rab11 and the subsequent 
NPC1L1 translocation to the cell surface ${ }^{31}$. Also high glucose levels increase the cellular uptake of cholesterol in cultured intestinal cells; this effect is due to the modulation of cholesterol transporters present in intestinal epithelial cells, being NPC1L1 and CD36 upregulated and SR-BI downregulated ${ }^{32}$. Glucose also increases NPC1L1 promoter activity in cultured intestinal cells, thus suggesting a transcriptional regulation ${ }^{33}$; the effect of glucose seems to be dependent on glucose metabolism as well as the activation of cellular protein phosphatases ${ }^{33}$. Whether these mechanisms could account for the altered cholesterol absorption observed in diabetic patients ${ }^{34}$ remains to be explored.

In contrast to NPC1, which is highly expressed and widely distributed in various tissues $^{35}$, NPC1L1 mRNA and protein are mostly expressed in the gastrointestinal tract, being the small intestine and especially enterocytes from the proximal (jejunum) region highly enriched in NPC1L1 $1^{14}$.

While in mice and rats NPC1L1 expression is restricted to the intestine ${ }^{5}$, in humans and in non-human primates, NPC1L1 is also expressed in the liver, within the canalicular membrane of hepatocytes, where it facilitates cholesterol uptake, thus potentially preventing excessive loss of biliary cholesterol ${ }^{3}$. Opposing the function for NPC1L1 in the liver, ABCG5 and ABCG8 promote the removal of sterols from the body through biliary excretion ${ }^{36}$. The acquisition of hepatic NPC1L1 expression could represent an evolutionary advantage to locally control the cholesterol content in the membrane of hepatocytes, which appears to be a relevant factor for the canalicular membrane to limit the cytotoxic effect of biliary acids ${ }^{37}$.

Recently, the possibility that epigenetics mechanisms could control NPC1L1 transcription and differential tissue localization was proposed. In animal models, increased DNA methylation was observed in the colon compared with jejunum and 
ileum and the treatment with a DNA methyltransferase inhibitor agent was associated with increased NPC1I1 expression in the colon ${ }^{38}$. A similar epigenetic mechanism was proposed to modulate also human NPC1L1 expression ${ }^{38}$.

\section{Mechanisms of NPC1L1-mediated intestinal cholesterol absorption}

Several pathways and multiple receptors/transporters are involved in intestinal cholesterol absorption ${ }^{1}$. As detailed above, NPC1L1 which is expressed at the apical membrane of enterocytes plays a crucial role in this process $^{14}$.

Several observations have suggested that the mechanism by which NPC1L1 mediates cholesterol uptake is through a clathrin-dependent endocytosis:

a) NPC1L1 cycles between plasma membrane and recycling endosome, a process coupled to cholesterol uptake that can be inhibited by blocking clathrin-mediated endocytosis $^{20}$;

b) caveolae-mediated endocytosis is not involved in the process of cholesterol absorption, as mice lacking caveolin-1 exhibit normal intestinal cholesterol absorption $^{39}$;

c) finally, NPC1L1 co-immunoprecipitates with proteins (a subunit of the adaptor protein complex AP2 and the clathrin heavy chain) essential for clathrin-dependent endocytosis $^{21}$. NPC1L1 contains a YVNXXF internalization motif located at the cytoplasmic C-terminal tail, a sequence that is highly conserved among mammalian NPC1L1 proteins and is not present in the homolog NPC1 ${ }^{40}$. The binding of cholesterol to the N-terminal domain of NPC1L1 induces the dissociation of YVNXXF-containing region from plasma membrane thus enabling the binding of the clathrin adaptor Numb, that, in turn, recruits clathrin/AP2 complex for internalization ${ }^{40}$. 
NPC1L1, following the binding of cholesterol to its $\mathrm{N}$-terminal domain ${ }^{18}$, forms cholesterol-enriched membrane microdomains on plasma membrane by interacting with lipid raft proteins including flotillin; these microdomains function as carriers for bulk of cholesterol ${ }^{41}$. NPC1L1-flotillins containing microdomains might provide a cholesterol-enriched region required to initiate the process of NPC1L1 endocytosis. In fact, in the presence of high cholesterol levels, the sterol-sensing domain of NPC1L1 might induce protein conformational changes promoting endocytosis ${ }^{41}$. The possibility that, during the assembly of these cholesterol-enriched microdomains, other unknown factors might be incorporated and activate the process of NPC1L1 endocytosis ${ }^{41}$, should be considered. NPC1L1 inhibitors limit the formation of these cholesterolenriched microdomains by disrupting the NPC1L1-flotillins complex ${ }^{41}$. 
Human loss of function mutations of NPC1L1 and cardiovascular disease

Given that pre-clinical data indicate the key relevance of NPC1L1 in determining cholesterol absorption, molecular approaches to inhibit NPC1L1 activity thus limiting cholesterol absorption and reducing plasma cholesterol levels have been explored ${ }^{42}$. A critical aspect to translate the relevance of NPC1L1 inhibition to the human context is the demonstration that this process results also in cardiovascular protection. While the gold standard is represented by a long clinical trial with cardiovascular hard events as endpoint, a parallel approach to estimate the potential efficacy of NPC1L1 targeting is the study of plasma lipid profile and cardiovascular outcome in subjects with naturally occurring DNA sequence variants that affect the activity/expression of NPC1L1. Although DNA sequence variants in NPC1L1 were associated with modest alterations in plasma LDL cholesterol levels ${ }^{43}$, a large screening in 7364 patients with coronary heart disease and in 14,728 controls without such disease identified 15 distinct NPC1L1 rare inactivating mutations ${ }^{6}$. Carriers of a single mutant NPC1L1 allele presented a significant reduction in plasma LDL-C levels $(12 \mathrm{mg} / \mathrm{dL}$ ) but, more importantly, they presented a relative reduction of $53 \%$ in coronary heart disease risk $^{6}$. This finding represents an elegant demonstration that genetically determined lifelong lower activity of NPC1L1 is associated with cardiovascular protection. Extrapolation of genetic findings into pharmacology needs some caution, indeed while genetic data provides a lifelong NPC1L1 lower expression, pharmacological treatment will start later in life and be limited in time. Therefore, the benefit in terms of cardiovascular risk reduction $(-53 \%)$ as a consequence of genetically driven (NPC1L1 inactivating mutations) LDL-C reduction $(-12 \mathrm{mg} / \mathrm{dL})$ will be much higher compared with the cardiovascular risk reduction observed in clinical trials with a similar degree of LDL-C reduction ${ }^{44-46}$. A finding which has been confirmed in all the analyses of lipid 
lowering genes ${ }^{47}$.

Human loss of function mutations of NPC1L1 and gallstone disease

Preclinical observations point to a protective role for NPC1L1 on cholesterol gallstone disease as a consequence of the reduction in bile secretion of cholesterol. Even in this context, the genetic approach is instrumental to investigate the impact of NPC1L1 inhibition on gallstone disease. Loss of function variations of NPC1L1, although associated with reduced risk of ischemic vascular disease, were initially associated with a modest but significant increased risk of symptomatic gallstone disease $^{48}$. However, this finding was not confirmed later, and indeed in a larger analysis, which included more than 100,000 subjects, no association between NPC1L1 polymorphisms and the risk of gallstone disease was observed ${ }^{49}$. Similarly, a genomewide association study of symptomatic gallbladder disease among women failed to observed any association of NPC1L1 polymorphisms with symptomatic gallbladder disease $(p=0.39)^{50}$. More importantly when the data from these three studies were combined, NPC1L1 inactivating variants were not associated with a significantly increased risk of symptomatic gallbladder disease. More importantly, this result is in line with data from pharmacological inhibition of NPC1L1 which excluded an increased risk of symptomatic gallbladder disease over an average 6-years follow-up in the IMPROVE-IT study ${ }^{9}$. 


\section{Experimental pharmacology of NPC1L1 inhibition}

Ezetimibe, a drug initially designed to inhibit cholesterol absorption for treating hypercholesterolemia, was later discovered to target NPC $1 \mathrm{~L} 1^{14,51}$. Both oxysterols and ezetimibe inhibit the formation of NPC1L1-flotillin-cholesterol microdomains; however, in contrast to oxysterols which compete with cholesterol for the $\mathrm{N}$-terminal domain of NPC1L1, ezetimibe binds to a region within a large extracellular domain (loop C) (Figure 1), which is distinct from the binding site of cholesterol and is located in the intestinal lumen ${ }^{52}$, thus inducing the dissociation of NPC1L1 from flotillin, preventing the formation of NPC1L1-flotillin-cholestrol microdomains ${ }^{41}$ and blocking the internalization of NPC1L1 and cholesterol in intestinal enterocytes ${ }^{53}$.

NPC1L1-deficient mice (NPC1L1 KO) exhibit a significantly decreased absorption of cholesterol $(-69 \%)$ compared with wild type mice. A similar extent of reduction in cholesterol absorption $(-70 \%)$ is observed in wild type mice treated with ezetimibe ${ }^{14}$. More importantly NPC1L1 KO mice are completely resistant to diet-induced hypercholesterolemia and present plasma and hepatic cholesterol levels similar to those of wild type mice treated with ezetimibe ${ }^{5,27}$.

On the other hand, transgenic mice expressing human NPC1L1 in hepatocytes present a $30 \%-60 \%$ increase in plasma cholesterol, mainly due to the accumulation of apoE-rich HDL, together with the reduction in biliary cholesterol concentration; in these animals ezetimibe restore both biliary and plasma cholesterol levels ${ }^{3,54}$.

Ezetimibe is rapidly absorbed from the gastrointestinal tract and transformed into its glucuronides (Figure 2). The main metabolite in human plasma is a phenolic glucuronide that accounts for about $90 \%$ of total ezetimibe. This glucuronide localizes more avidly in the intestine compared with ezetimibe and exhibit similar or even higher cholesterol-lowering activity compared with the parent compound ${ }^{17,55}$. The 
plasma concentration-time profile of ezetimibe and its conjugated metabolite shows multiple peaks, indicating enterohepatic recycling ${ }^{56}$.

Enterocytes isolated from NPC1L1-deficient mice do not exhibit detectable binding ability to radiolabeled ezetimibe glucuronide, in contrast to the high level of binding observed in enterocytes isolated from wild type mice ${ }^{51}$, clearly reaffirming that NPC1L1 is the direct molecular target of ezetimibe.

The deficiency of NPC1L1 in atherosclerosis prone animals such as the apoE ${ }^{-/-}$ mice is associated with a significantly reduced ability of these animals to absorb cholesterol compared with that of $a \mathrm{apE}^{-/-57}$. The most remarkable effect of NPC1L1 deletion in this animal model is the almost complete protection from the development of atherosclerotic lesions; this effect is similar to that obtained in apoE ${ }^{-/-}$mice treated with ezetimibe ${ }^{57}$.

Cholesterol feeding of NPC1L1/-/LDLR ${ }^{-/-}$knockout mice genetically modified to overexpress human NPC1L1 only in the gastrointestinal tract resulted in a significantly increased cholesterol absorption, compared with the double knockout mice ${ }^{58}$, which was associated with increased apolipoprotein B100 and B48 secretion and plasma cholesterol levels ${ }^{58}$. These findings suggested that, at least in animal models, NPC1L1-mediated cholesterol absorption is a major determinant of atherogenic apoB-containing lipoproteins.

The reduction of cholesterol absorption, promotes, as a feedback mechanism to maintain cholesterol homeostasis, the increase of reverse cholesterol transport $(\mathrm{RCT})^{59}$, a process involved in the transport of cholesterol from peripheral cells back to the liver. This mechanism is common in mice genetically manipulated to present reduced cholesterol absorption ${ }^{59}$, but is also observed in mice ${ }^{60,61}$ and hamsters ${ }^{62}$ following ezetimibe administration. These findings suggest that the inhibition of 
cholesterol absorption may exert an atheroprotective effects also by promoting the removal of cholesterol excess from peripheral tissues.

As the maintenance of cholesterol homeostasis is critical for several biological processes and cholesterol synthesis and absorption are inversely regulated to maintain cholesterol balance, it is not surprising that the inhibition of endogenous cholesterol absorption activates also a series of mechanistic feedbacks resulting in increased endogenous cholesterol synthesis ${ }^{63}$. Thus, while statins inhibit hepatic synthesis of cholesterol and increase cholesterol absorption markers, ezetimibe negatively affects cholesterol absorption but also increases cholesterol synthesis ${ }^{63}$. These pharmacological responses may reduce the efficacy of the single drugs, but also set the stage for combining the two pharmacological approaches with the aim of limiting both cholesterol absorption and synthesis. In this context, it is worth to mention that statins cause elevation of plasma PCSK9, a proprotein convertase that promotes LDLR degradation, and this effect can reduce the cholesterol-lowering efficacy of statins ${ }^{64}$. However, in healthy subjects, while a 2-week treatment with simvastatin $(40 \mathrm{mg}$ ) resulted in the upregulation of circulating PCSK9 levels, neither ezetimibe alone nor the addition of ezetimibe to simvastatin induced an increase in PCSK9 levels ${ }^{65}$. This finding could perhaps be the consequence of the limited absolute LDL-C reduction induced by ezetimibe on the top of simvastatin which may not be enough to further upregulate PCSK9 expression. In line with this, modest LDL-C lowering such as that observed with simvastatin $10 \mathrm{mg}$ does not increase PCSK9 levels ${ }^{66}$. The observation that key players in cholesterol metabolism, including HMGCoA reductase, LDL-R, PCSK9 and NPC1L1 are cross-regulated depending on how cholesterol homeostasis is targeted, reinforce the rationale for the use of pharmacological approaches combining ezetimibe and a statin. 


\section{Clinical pharmacology of the NPC1L1 inhibitor ezetimibe}

\section{Inhibition of NPC1L1 by ezetimibe and LDL-C lowering}

LDL-C lowering represents the primary target of therapy in the primary and secondary prevention of cardiovascular disease. Statins, which inhibit endogenous cholesterol biosynthesis, mainly in the liver, are the first-choice drug for the treatment of hypercholesterolemia ${ }^{67}$. The observation that the extent of plasma LDL-C reduction

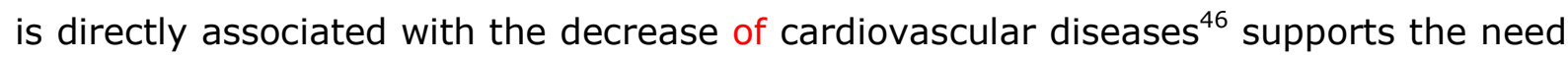
of novel pharmacological approaches beyond statins for patients with hypercholesterolaemia ${ }^{42,68-70}$. Among them, ezetimibe possesses a mechanism of action that is complementary to that of statins, and thus the combination statinezetimibe represents a successful approach to improve the management of hypercholesterolemia and the prevention of cardiovascular disease. In addition, the residual risk of recurrent cardiovascular events even with aggressive statin-based cholesterol-lowering therapies and concerns regarding the safety and adverse events observed with high-dose statins further supported the search for lipid-lowering therapies with a complementary mechanism of action ${ }^{71,72}$.

A large number of clinical trials have evaluated the effect of adding ezetimibe to statins, showing an average additional LDL-C levels reduction of about $20 \%{ }^{42,73-75}$ (Table 1 ). These findings have been confirmed in a pooled analysis of over 21,000 subjects from 27 clinical trials that compared the effect of statin versus statin plus ezetimibe and showed that the combination therapy was more effective at reducing LDL-C levels (treatment difference: $-15.1 \%, p<0.0001)^{76}$. Overall, the lipid profile was greatly improved with the combination therapy compared to similar statin doses and in most of the cases also when higher statin doses were used. Furthermore, safety profiles were comparable among the treatments. 
Moreover, a retrospective, observational study showed that both LDL-C lowering and goal attainment were significantly higher in patients with CHD or CHD riskequivalent treated with ezetimibe added to current statin therapy compared with patients who titrated the statin doses $(-26 \% \text { to } 27 \% \text { vs }-8.8 \% \text { to }-9.8 \%)^{77}$. Finally, ezetimibe seems to have beneficial effect also on RCT in humans, similarly to what observed in animal models, resulting in an increased flux of cholesterol to feces in hyperlipidemic patients ${ }^{78}$.

The higher efficacy of ezetimibe combined with statin for the treatment of atherogenic dyslipidemia has been recently confirmed also in diabetic patients. The RESEARCH (Recognized Effect of Statin and Ezetimibe therapy for Achieving LDL-C Goal) trial compared, in type 2 diabetic subjects who failed to achieve their LDL-C target, the 12-week effect of a high-potency statin plus ezetimibe (atorvastatin $10 \mathrm{mg}$ or pitavastatin $1 \mathrm{mg}$ + ezetimibe $10 \mathrm{mg}$ ) versus doubled dose of statin (atorvastatin $20 \mathrm{mg}$ or pitavastatin $2 \mathrm{mg})^{79}$. The combination ezetimibe+statin was more effective at reducing LDL-C levels than doubling the dose of statins $(-24.6 \%$ vs $-10.9 \%$, respectively) $)^{79}$ and a significantly higher percentage of subjects reached their LDL-C goals in the group treated with ezetimibe+statin than in the group treated with a doubled statin dose $(89.3 \% \text { vs } 51 \%, \mathrm{p}<0.0001)^{79}$. In addition, the treatment with ezetimibe+statin improved the atherogenic plasma lipid profile more effectively than statin therapy, including a more pronounced reduction of small dense LDL levels $(-20.5 \%$ vs $-3.7 \%)$ and remnant-like particle cholesterol $(-19.7 \% \text { vs }+5.5 \%)^{79}$. Diabetic patients have been suggested to benefit from combination therapy ezetimibe+statin more than non-diabetic subjects, as they seem to achieve significantly higher reduction in LDL-C and non-HDL-C; this might be due to a higher expression of NPC1L1 in diabetic patients, but a defined explanation is still lacking ${ }^{80}$. 
Besides, it emerged that statin use may impair glucose tolerance and increase the risk of new-onset type 2 diabetes, although the benefits of cardiovascular risk reduction still largely exceeds the risk of incident diabetes ${ }^{81}$. On the contrary, current data suggest that ezetimibe ameliorates glycemic control and insulin sensitivity ${ }^{82}$. However, conclusive results are still lacking, as most clinical trials did not evaluate the impact of ezetimibe on glucose metabolism and commonly tested the effect of ezetimibe in combination with a $\operatorname{statin}^{82}$. An analysis of the IMPROVE-IT trial suggests that type 2 diabetic patients with a recent acute coronary syndrome may benefit from the addition of ezetimibe to a statin therapy: in fact, in this subgroup of patients, ezetimibe added to a statin lowered LDL-C more than the statin alone $(43 \mathrm{mg} / \mathrm{dL}$ vs $23 \mathrm{mg} / \mathrm{dL}$ ) and reduced the relative cardiovascular risk by $14 \%^{83}$. In non-diabetics this effect was less evident, with a $2 \%$ relative risk reduction ${ }^{83}$.

\section{Inhibition of NPC1L1 by ezetimibe and inflammation}

Statins were proposed to have pleiotropic effects beyond lipid-lowering; among them, the ability to reduce inflammation, a process that play a crucial role in the atherogenic process ${ }^{84}$. Indeed, studies designed to evaluate the effect of ezetimibe on inflammatory markers in subjects at increased cardiovascular risk showed a decreased expression of markers of oxidative stress and inflammation ${ }^{85-87}$. This may suggest that the beneficial effect of ezetimibe on inflammation could depend on the degree of plasma cholesterol reduction achieved, further supporting the correlation between plasma cholesterol and the immuno-inflammatory status ${ }^{88-91}$.

Conversely, no effects were observed on the amount of circulating microparticles or endothelial progenitor cells in subjects with coronary heart disease under antiplatelet therapy and treated with the combination ezetimibe/simvastatin, in spite 
of a significant increase of endothelial function measured as flow-mediated dilatation $^{92}$. A lack of effect on microparticles and endothelial progenitor cells by ezetimibe treatment was reported also in patients at high-risk for coronary heart disease $e^{93}$.

\section{Inhibition of NPC1L1 by ezetimibe and carotid and coronary atherosclerosis}

Some studies have raised concerns about the efficacy of ezetimibe treatment in the prevention of cardiovascular disease. The ENHANCE (Ezetimibe and Simvastatin in Hypercholesterolemia Enhances Atherosclerosis Regression) trial evaluated the effect of the administration of $10 \mathrm{mg}$ ezetimibe in combination with $80 \mathrm{mg}$ simvastatin on the progression of atherosclerosis in patients with familial hypercholesterolemia and found that the addition of ezetimibe to the highest recommended dose of simvastatin, although further reducing LDL-C levels, did not result in reduction of the intima-media thickness of the carotid artery wall ${ }^{94}$ (Table 2).

This result was confirmed by the ARBITER 6-HALTS (Arterial Biology for the Investigation of the Treatment Effects of Reducing Cholesterol 6-HDL and LDL Treatment Strategies in Atherosclerosis) trial that evaluated the effect of adding ezetimibe or extended-release niacin to a chronic statin therapy in patients with

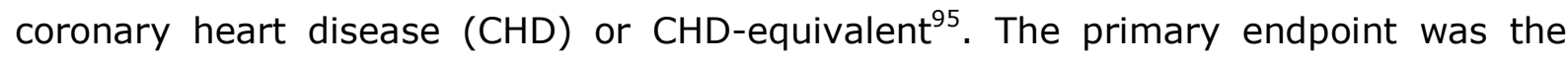
change in mean carotid intima-media thickness (CIMT): while niacin induced a significant regression in mean CIMT, ezetimibe did not change this parameter and instead increased cumulative drug exposure resulted in CIMT progression in patients treated with ezetimibe ${ }^{95}$ (Table 2). It appears that the inconclusive results observed with these studies are dependent on the starting status of the carotid arteries, i.e if the subjects present with IMT values in the normal range the likelihood that an 
hypolipidaemic treatment will be effective is quite low, thus perhaps explaining the findings of the ENHANCE trial.

The Simvastatin and Ezetimibe in Aortic Stenosis (SEAS) trial has been designed to assess the effects of long-term (4.3 years) treatment with ezetimibe+simvastatin in patients with asymptomatic, mild-to-moderate aortic-valve stenosis ${ }^{96}$ (Table 2). This intervention resulted in an average reduction of LDL-C of at least $50 \%$ compared with placebo; however, no effect on aortic-valve events was observed, despite a reduction of ischemic cardiovascular events ${ }^{96}$. The reduction of ischemic events was significant in subjects with less severe aortic stenosis at baseline; the lack of effect on ischemic events in more severe aortic stenosis at baseline may be explained with the shorter duration of lipid-lowering therapy before valve replacement; aortic-valve associated events did not decrease even for the mildest degree of aortic stenosis ${ }^{97}$.

On the other hand, the Stop Atherosclerosis in Native Diabetics Study (SANDS) trial showed that, in subjects with type 2 diabetes, aggressive lipid-lowering treatment with ezetimibe+statin induced the regression of carotid IMT, as compared with standard lipid-lowering therapy that resulted in a modest carotid IMT progression ${ }^{98}$. When comparing aggressive statin monotherapy with aggressive statin+ezetimibe, the last induced a greater regression of CIMT after 36-month therapy ${ }^{99}$, indicating that ezetimibe is effective in reversing carotid atherosclerosis. A similar result was reported in another study showing that adding ezetimibe to statin monotherapy significantly reduces LDL-C levels and decreases IMT in a high-risk group of subjects with thickened carotid walls ${ }^{100}$. Similarly, the addition of ezetimibe to the current lipidlowering regimen of patients attending vascular prevention clinics resulted in the regression of carotid total plaque area ${ }^{101}$ (Table 2). 
A significant incremental reduction of coronary plaques has been recently reported in subjects who received ezetimibe in addition to usual rosuvastatin monotherapy in patients with stable coronary artery disease, with a percent change in plaque volume greater in the group of combined therapy compared with rosuvastatin alone $(-13.2 \% \text { vs }-3.1 \%, p=0.05)^{102}$. In this study, the addition of ezetimibe reduced was more effective in reducing not only LDL-C but also TG, non-HDL-C and small dense LDL (sd-LDL), being this last associated with increased risk of coronary artery disease; the reduction in plaque volume correlated not only with reduction of LDL-C but also with levels of sd-LDL at follow-up ${ }^{102}$ (Table 2). This finding is in agreement with the results of another study showing that the addition of ezetimibe to fluvastatin therapy resulted in a major increase of the minimum fibrous thickness of lipid-rich plaque compared with fluvastatin alone, with a negative correlation between the change in minimum fibrous cap thickness and change in LDL- $\mathrm{C}^{103}$. Altogether these observations suggest that ezetimibe addition to statin therapy may affect plaque stabilization (Table 2).

\section{NPC1L1 inhibition and cardiovascular disease}

Although a large number of studies showed that adding ezetimibe to a statin therapy further reduces LDL-C levels by an additional $23-24 \%^{76,104}$, to date few clinical trials have evaluated the effect of adding ezetimibe to statin therapy on clinical cardiovascular outcomes. The Study of Heart and Renal Protection (SHARP) was designed to evaluate the effect of the combination ezetimibe+simvastatin in patients with moderate-to-severe kidney disease ${ }^{105}$. Patients randomized to ezetimibe+simvastatin or to placebo were followed-up for 4.9 years; LDL-C-lowering with ezetimibe+simvastatin resulted in a significantly reduced incidence $(-17 \%)$ of major atherosclerotic events ${ }^{105}$ although it did not slow kidney disease progression ${ }^{106}$. 
When patients with CKD and LDL-C levels above $120 \mathrm{mg} / \mathrm{dL}$ (despite statin therapy) were randomized to receive double dose of statin or ezetimibe in addition to the usual dose of statin, during the first year of follow-up, in spite of similar LDL-C reduction the incidence of adverse effects was significantly lower in the combination therapy group compared with the high dose of $\operatorname{statin}^{107}$. These findings suggest that combining a statin with ezetimibe may help to safely reduce cardiovascular complications of highrisk patients with chronic kidney disease.

The Improved Reduction of Outcomes: Vitoryn Efficacy International Trial (IMPROVE-IT) evaluated the effect of ezetimibe $(10 \mathrm{mg})$ combined with simvastatin (40 mg) or simvastatin (40 mg) alone in patients who had had an acute coronary syndrome within the preceding 10 days and LDL-C levels within the range of recommended values ${ }^{9}$. After a median follow-up of 6 years, median time-weighted average LDL-C level was significantly lower in the group treated with ezetimibe+simvastatin compared with patients treated with simvastatin alone ( $53.7 \mathrm{mg} / \mathrm{dL}$ vs $69.5 \mathrm{mg} / \mathrm{dL}, \mathrm{p}<0.001$ ); in addition, a higher proportion of patients treated with ezetimibe+simvastatin reached a dual goal including a LDL-C level $<70$ $\mathrm{mg} / \mathrm{dL}(1.8 \mathrm{mmol} / \mathrm{L})^{9}$. Also cardiovascular outcomes were improved in the group treated with ezetimibe+simvastatin; indeed the primary end point (a composite of cardiovascular death, nonfatal myocardial infarction (MI), unstable angina requiring hospitalization, coronary revascularization, nonfatal stroke) was lower in ezetimibe+simvastatin group than in simvastatin group $(32.7 \% \text { vs } 34.7 \%, p=0.016)^{9}$; the risk of any myocardial infarction or ischemic stroke were significantly lower in the ezetimibe+simvastatin group than in simvastatin group (any MI: $13.1 \%$ vs $14.8 \%$, $\mathrm{p}=0.002$; IS: $3.4 \%$ vs $4.1 \%, \mathrm{p}=0.008$ ), as were other prespecified end points, while no differences were observed in terms of safety between the two groups ${ }^{9}$ (Table 2 ). 
The benefits of adding ezetimibe seemed to be more evident in diabetics and in older ( $\geq 75$ years) patients $^{9}$. A recent analysis of the IMPROVE-IT trial showed that patients reaching the dual LDL-C and hs-CRP targets had the lowest absolute and relative risk of recurrent events, independently of the pharmacological approach used to achieve the target levels ${ }^{108}$. These findings support the concept that LDL-C lowering per se translates into clinical benefits ${ }^{9}$.

\section{NPC1L1 inhibition in familial hypercholesterolemia}

Patients with homozygous familial hypercholesterolemia (HoFH) have a very high risk of premature coronary artery disease; statins, that represent the main lipidlowering drug class, may be effective in some HoFH patients, but this requires the presence of an at least in part functional $\operatorname{LDLR}^{109,110}$. Novel options are becoming available for the treatment of $\mathrm{HoFH}$ which include apoB gene silencing ${ }^{69}$ as well as MTP inhibitors ${ }^{42}$ but also inhibitors on NPC1L1. Indeed, the addition of ezetimibe to atorvastatin or simvastatin for 12 -week induced a significant reduction in LDL-C levels ( $14 \%$ to $20.5 \%$ ) compared with statins alone ${ }^{111}$.

In patients with heterozygous $\mathrm{FH}(\mathrm{HeFH})$, which exhibit a less severe phenotype and a lower cardiovascular risk compared with $\mathrm{HoFH}$, co-administration of ezetimibe with a statin resulted in a further decrease of LDL-C levels ${ }^{112}$. Of note, in this cohort a wide inter-individual variability response to ezetimibe was observed; indeed, ezetimibe was less effective in statin hyper-responders (who also present with a higher cholesterol synthesis and lower cholesterol absorption) and vice versa ${ }^{112}$. However, the addition of ezetimibe to the highest recommended dose of simvastatin did not result in a further reduction of the carotid intima-media thickness compared with simvastatin alone in patients with $\mathrm{FH}$, despite LDL-C and C-reactive protein levels were lowered to a larger extent in patients treated with the combination therapy ${ }^{94}$. 
Given that these patients were treated for many years with statins before the study, it is possible that the benefit of the therapy had already occurred and the resultant fibrotic, calcified lesion may not further benefit of an additional LDL-C lowering ${ }^{113}$. Of note, another study performed in HeFH with a history of acute myocardial infarction or with carotid lesions but no history of cardiovascular events treated for 30 months with the combination ezetimibe/simvastatin showed a considerable reduction of LDL-C, an improvement of lipid profile and inflammatory markers and a significant reduction of the mean of the carotid IMT in both groups ${ }^{114}$.

\section{Other NPC1L1 inhibitors}

To date, ezetimibe represents the only inhibitor of NPC1L1 available for clinical use. In an effort to identify new cholesterol absorption inhibitors, some studies have evaluated the possibility to obtain ezetimibe analogs with superior ability to inhibit cholesterol absorption. In one study, six new amide ezetimibe analogs have been synthesized; these compounds exhibited low toxicity and a significant ability to inhibit cholesterol uptake in cells overexpressing human NPC1L1; among them, 3 compounds were tested also in vivo in mice, showing the ability to reduce hepatic and intestinal cholesterol levels ${ }^{115}$ (Figure 3). The same authors, in a previous study synthesized two new amino-ß-lactam derivatives that efficiently inhibited cholesterol absorption comparable to ezetimibe ${ }^{116}$ (Figure 3).

Although several compounds with structural similarities to ezetimibe were designed, few of them were reported to lower cholesterol absorption ${ }^{96-98}$. Eight new 2-azetidinone analogs of ezetimibe have been designed through in silico docking experiments with the crystal structure of NPC1L1 and synthesized; some of these molecules have significant lipid-lowering effects, comparable to those of ezetimibe ${ }^{117}$. 


\section{Conclusions}

Experimental and human genetics evidences point to a critical role for NPC1L1 in intestinal cholesterol absorption. NPC1L1 inhibition provides a complimentary approach to decrease plasma cholesterol levels beyond statins which inhibit liver cholesterol biosynthesis. The possibility of targeting two pathways involved in cholesterol body homeostasis allows to maintain statins doses within the lower range without affecting the efficacy in reducing LDL-C levels and the risk of cardiovascular events. Therefore the pharmaceutical research is highly active in identifying chemical requirements to design novel ezetimibe analogs with increased efficiency thus paving the road for novel dual therapies to reduce hypercholesterolemia and the associated cardiovascular risk. 


\section{Legends to the Figures}

Figure 1. Structure of human NPC1L1. NPC1L1 contains 13 transmembrane domains, comprising a sterol-sensing domain (SSD), a region of 180 amino acids that forms five membrane-spanning helices with short intervening loops. The extracellular $\mathrm{N}$-terminal domain of NPC1L1 directly binds cholesterol, while ezetimibe binds to the Ioop C.

Figure 2. Main metabolites of ezetimibe.

Figure 3. Structures of ezetimibe analogs. 


\section{References}

[1] Wang, D.Q. Regulation of intestinal cholesterol absorption. Annu Rev Physiol, 2007, 69 (221-248.

[2] Wang, L.J.; Song, B.L. Niemann-Pick C1-Like 1 and cholesterol uptake. Biochim Biophys Acta, 2012, 1821 (7), 964-972.

[3] Temel, R.E.; Tang, W.; Ma, Y.; Rudel, L.L.; Willingham, M.C.; loannou, Y.A.; Davies, J.P.; Nilsson, L.M.; $\mathrm{Yu}, \mathrm{L}$. Hepatic Niemann-Pick C1-like 1 regulates biliary cholesterol concentration and is a target of ezetimibe. J Clin Invest, 2007, 117 (7), 1968-1978.

[4] Yamanashi, Y.; Takada, T.; Suzuki, H. Niemann-Pick C1-like 1 overexpression facilitates ezetimibesensitive cholesterol and beta-sitosterol uptake in CaCo-2 cells. J Pharmacol Exp Ther, 2007, 320 (2), 559564.

[5] Davies, J.P.; Scott, C.; Oishi, K.; Liapis, A.; Ioannou, Y.A. Inactivation of NPC1L1 causes multiple lipid transport defects and protects against diet-induced hypercholesterolemia. J Biol Chem, 2005, 280 (13), 12710-12720.

[6] Stitziel, N.O.; Won, H.H.; Morrison, A.C.; Peloso, G.M.; Do, R.; Lange, L.A.; Fontanillas, P.; Gupta, N.; Duga, S.; Goel, A.; Farrall, M.; Saleheen, D.; Ferrario, P.; Konig, I.; Asselta, R.; Merlini, P.A.; Marziliano, N.; Notarangelo, M.F.; Schick, U.; Auer, P.; Assimes, T.L.; Reilly, M.; Wilensky, R.; Rader, D.J.; Hovingh, G.K.; Meitinger, T.; Kessler, T.; Kastrati, A.; Laugwitz, K.L.; Siscovick, D.; Rotter, J.I.; Hazen, S.L.; Tracy, R.; Cresci, S.; Spertus, J.; Jackson, R.; Schwartz, S.M.; Natarajan, P.; Crosby, J.; Muzny, D.; Ballantyne, C.; Rich, S.S.; O'Donnell, C.J.; Abecasis, G.; Sunyaev, S.; Nickerson, D.A.; Buring, J.E.; Ridker, P.M.; Chasman, D.I.; Austin, E.; Ye, Z.; Kullo, I.J.; Weeke, P.E.; Shaffer, C.M.; Bastarache, L.A.; Denny, J.C.; Roden, D.M.; Palmer, C.; Deloukas, P.; Lin, D.Y.; Tang, Z.Z.; Erdmann, J.; Schunkert, H.; Danesh, J.; Marrugat, J.; Elosua, R.; Ardissino, D.; McPherson, R.; Watkins, H.; Reiner, A.P.; Wilson, J.G.; Altshuler, D.; Gibbs, R.A.; Lander, E.S.; Boerwinkle, E.; Gabriel, S.; Kathiresan, S. Inactivating mutations in NPC1L1 and protection from coronary heart disease. N Engl J Med, 2014, 371 (22), 2072-2082.

[7] Davis, H.R.; Veltri, E.P. Zetia: inhibition of Niemann-Pick C1 Like 1 (NPC1L1) to reduce intestinal cholesterol absorption and treat hyperlipidemia. J Atheroscler Thromb, 2007, 14 (3), 99-108.

[8] http://www.merck.com/product/usa/pi circulars/z/zetia/zetia pi.pdf. (Accessed October 7, 2015) [9] Cannon, C.P.; Blazing, M.A.; Giugliano, R.P.; McCagg, A.; White, J.A.; Theroux, P.; Darius, H.; Lewis, B.S.; Ophuis, T.O.; Jukema, J.W.; De Ferrari, G.M.; Ruzyllo, W.; De Lucca, P.; Im, K.; Bohula, E.A.; Reist, C.; Wiviott, S.D.; Tershakovec, A.M.; Musliner, T.A.; Braunwald, E.; Califf, R.M. Ezetimibe Added to Statin Therapy after Acute Coronary Syndromes. N Engl J Med, 2015, 372 (25), 2387-2397.

[10] Yu, X.H.; Qian, K.; Jiang, N.; Zheng, X.L.; Cayabyab, F.S.; Tang, C.K. ABCG5/ABCG8 in cholesterol excretion and atherosclerosis. Clin Chim Acta, 2014, 428 (82-88.

[11] Davies, J.P.; Levy, B.; loannou, Y.A. Evidence for a Niemann-pick C (NPC) gene family: identification and characterization of NPC1L1. Genomics, 2000, 65 (2), 137-145.

[12] Jia, L.; Betters, J.L.; Yu, L. Niemann-pick C1-like 1 (NPC1L1) protein in intestinal and hepatic cholesterol transport. Annu Rev Physiol, 2011, 73 (239-259.

[13] Carstea, E.D.; Morris, J.A.; Coleman, K.G.; Loftus, S.K.; Zhang, D.; Cummings, C.; Gu, J.; Rosenfeld, M.A.; Pavan, W.J.; Krizman, D.B.; Nagle, J.; Polymeropoulos, M.H.; Sturley, S.L.; loannou, Y.A.; Higgins, M.E.; Comly, M.; Cooney, A.; Brown, A.; Kaneski, C.R.; Blanchette-Mackie, E.J.; Dwyer, N.K.; Neufeld, E.B.; Chang, T.Y.; Liscum, L.; Strauss, J.F., 3rd; Ohno, K.; Zeigler, M.; Carmi, R.; Sokol, J.; Markie, D.; O'Neill, R.R.; van Diggelen, O.P.; Elleder, M.; Patterson, M.C.; Brady, R.O.; Vanier, M.T.; Pentchev, P.G.; Tagle, D.A. NiemannPick C1 disease gene: homology to mediators of cholesterol homeostasis. Science, 1997, 277 (5323), 228231.

[14] Altmann, S.W.; Davis, H.R., Jr.; Zhu, L.J.; Yao, X.; Hoos, L.M.; Tetzloff, G.; Iyer, S.P.; Maguire, M.; Golovko, A.; Zeng, M.; Wang, L.; Murgolo, N.; Graziano, M.P. Niemann-Pick C1 Like 1 protein is critical for intestinal cholesterol absorption. Science, 2004, 303 (5661), 1201-1204. 
[15] Iyer, S.P.; Yao, X.; Crona, J.H.; Hoos, L.M.; Tetzloff, G.; Davis, H.R., Jr.; Graziano, M.P.; Altmann, S.W. Characterization of the putative native and recombinant rat sterol transporter Niemann-Pick C1 Like 1 (NPC1L1) protein. Biochim Biophys Acta, 2005, 1722 (3), 282-292.

[16] Yu, L. The structure and function of Niemann-Pick C1-like 1 protein. Curr Opin Lipidol, 2008, 19 (3), 263-269.

[17] Wang, J.; Chu, B.B.; Ge, L.; Li, B.L.; Yan, Y.; Song, B.L. Membrane topology of human NPC1L1, a key protein in enterohepatic cholesterol absorption. J Lipid Res, 2009, 50 (8), 1653-1662.

[18] Zhang, J.H.; Ge, L.; Qi, W.; Zhang, L.; Miao, H.H.; Li, B.L.; Yang, M.; Song, B.L. The N-terminal domain of NPC1L1 protein binds cholesterol and plays essential roles in cholesterol uptake. J Biol Chem, 2011, 286 (28), 25088-25097.

[19] Kwon, H.J.; Palnitkar, M.; Deisenhofer, J. The structure of the NPC1L1 N-terminal domain in a closed conformation. PLoS One, 2011, 6 (4), e18722.

[20] Yu, L.; Bharadwaj, S.; Brown, J.M.; Ma, Y.; Du, W.; Davis, M.A.; Michaely, P.; Liu, P.; Willingham, M.C.; Rudel, L.L. Cholesterol-regulated translocation of NPC1L1 to the cell surface facilitates free cholesterol uptake. J Biol Chem, 2006, 281 (10), 6616-6624.

[21] Ge, L.; Wang, J.; Qi, W.; Miao, H.H.; Cao, J.; Qu, Y.X.; Li, B.L.; Song, B.L. The cholesterol absorption inhibitor ezetimibe acts by blocking the sterol-induced internalization of NPC1L1. Cell Metab, 2008, 7 (6), 508-519.

[22] Duval, C.; Touche, V.; Tailleux, A.; Fruchart, J.C.; Fievet, C.; Clavey, V.; Staels, B.; Lestavel, S. Niemann-Pick C1 like 1 gene expression is down-regulated by LXR activators in the intestine. Biochem Biophys Res Commun, 2006, 340 (4), 1259-1263.

[23] Iwayanagi, Y.; Takada, T.; Suzuki, H. HNF4alpha is a crucial modulator of the cholesterol-dependent regulation of NPC1L1. Pharm Res, 2008, 25 (5), 1134-1141.

[24] Iwayanagi, Y.; Takada, T.; Tomura, F.; Yamanashi, Y.; Terada, T.; Inui, K.; Suzuki, H. Human NPC1L1 expression is positively regulated by PPARalpha. Pharm Res, 2011, 28 (2), 405-412.

[25] van der Veen, J.N.; Kruit, J.K.; Havinga, R.; Baller, J.F.; Chimini, G.; Lestavel, S.; Staels, B.; Groot, P.H.; Groen, A.K.; Kuipers, F. Reduced cholesterol absorption upon PPARdelta activation coincides with decreased intestinal expression of NPC1L1. J Lipid Res, 2005, 46 (3), 526-534.

[26] Kawase, A.; Araki, Y.; Ueda, Y.; Nakazaki, S.; Iwaki, M. Impact of a high-cholesterol diet on expression levels of Niemann-Pick C1-like 1 and intestinal transporters in rats and mice. Eur J Drug Metab Pharmacokinet, 2015.

[27] Davis, H.R., Jr.; Zhu, L.J.; Hoos, L.M.; Tetzloff, G.; Maguire, M.; Liu, J.; Yao, X.; Iyer, S.P.; Lam, M.H.; Lund, E.G.; Detmers, P.A.; Graziano, M.P.; Altmann, S.W. Niemann-Pick C1 Like 1 (NPC1L1) is the intestinal phytosterol and cholesterol transporter and a key modulator of whole-body cholesterol homeostasis. J Biol Chem, 2004, 279 (32), 33586-33592.

[28] Telford, D.E.; Sutherland, B.G.; Edwards, J.Y.; Andrews, J.D.; Barrett, P.H.; Huff, M.W. The molecular mechanisms underlying the reduction of LDL apoB-100 by ezetimibe plus simvastatin. J Lipid Res, 2007, 48 (3), 699-708.

[29] Lee, E.S.; Seo, H.J.; Back, S.S.; Han, S.H.; Jeong, Y.J.; Lee, J.W.; Choi, S.Y.; Han, K. Transcriptional Regulation of Niemann-Pick C1-like 1 (NPC1L1) Gene by Liver Receptor Homolog-1 (LRH-1). BMB Rep, 2015. [30] Zhou, L.; Yang, H.; Lin, X.; Okoro, E.U.; Guo, Z. Cholecystokinin elevates mouse plasma lipids. PLoS One, 2012, 7 (12), e51011.

[31] Zhou, L.; Yang, H.; Okoro, E.U.; Guo, Z. Up-regulation of cholesterol absorption is a mechanism for cholecystokinin-induced hypercholesterolemia. J Biol Chem, 2014, 289 (19), 12989-12999.

[32] Ravid, Z.; Bendayan, M.; Delvin, E.; Sane, A.T.; Elchebly, M.; Lafond, J.; Lambert, M.; Mailhot, G.; Levy, E. Modulation of intestinal cholesterol absorption by high glucose levels: impact on cholesterol transporters, regulatory enzymes, and transcription factors. Am J Physiol Gastrointest Liver Physiol, 2008, 295 (5), G873-885. 
[33] Malhotra, P.; Boddy, C.S.; Soni, V.; Saksena, S.; Dudeja, P.K.; Gill, R.K.; Alrefai, W.A. D-Glucose modulates intestinal Niemann-Pick C1-like 1 (NPC1L1) gene expression via transcriptional regulation. Am J Physiol Gastrointest Liver Physiol, 2012, 304 (2), G203-210.

[34] Tomkin, G.H.; Owens, D. Dyslipidaemia of diabetes and the intestine. World J Diabetes, 2015, 6 (7), 970-977.

[35] Loftus, S.K.; Morris, J.A.; Carstea, E.D.; Gu, J.Z.; Cummings, C.; Brown, A.; Ellison, J.; Ohno, K.; Rosenfeld, M.A.; Tagle, D.A.; Pentchev, P.G.; Pavan, W.J. Murine model of Niemann-Pick C disease: mutation in a cholesterol homeostasis gene. Science, 1997, 277 (5323), 232-235.

[36] Brown, J.M.; Yu, L. Opposing Gatekeepers of Apical Sterol Transport: Niemann-Pick C1-Like 1 (NPC1L1) and ATP-Binding Cassette Transporters G5 and G8 (ABCG5/ABCG8). Immunol Endocr Metab Agents Med Chem, 2009, 9 (1), 18-29.

[37] Oude Elferink, R.P.; Paulusma, C.C.; Groen, A.K. Hepatocanalicular transport defects: pathophysiologic mechanisms of rare diseases. Gastroenterology, 2006, 130 (3), 908-925.

[38] Malhotra, P.; Soni, V.; Kumar, A.; Anbazhagan, A.N.; Dudeja, A.; Saksena, S.; Gill, R.K.; Dudeja, P.K.; Alrefai, W.A. Epigenetic modulation of intestinal cholesterol transporter Niemann-Pick C1-like 1 (NPC1L1) gene expression by DNA methylation. J Biol Chem, 2014, 289 (33), 23132-23140.

[39] Valasek, M.A.; Weng, J.; Shaul, P.W.; Anderson, R.G.; Repa, J.J. Caveolin-1 is not required for murine intestinal cholesterol transport. J Biol Chem, 2005, 280 (30), 28103-28109.

[40] Li, P.S.; Fu, Z.Y.; Zhang, Y.Y.; Zhang, J.H.; Xu, C.Q.; Ma, Y.T.; Li, B.L.; Song, B.L. The clathrin adaptor Numb regulates intestinal cholesterol absorption through dynamic interaction with NPC1L1. Nat Med, 2014, 20 (1), 80-86.

[41] Ge, L.; Qi, W.; Wang, L.J.; Miao, H.H.; Qu, Y.X.; Li, B.L.; Song, B.L. Flotillins play an essential role in Niemann-Pick C1-like 1-mediated cholesterol uptake. Proc Natl Acad Sci U S A, 2011, 108 (2), 551-556.

[42] Norata, G.D.; Ballantyne, C.M.; Catapano, A.L. New therapeutic principles in dyslipidaemia: focus on LDL and Lp(a) lowering drugs. Eur Heart J, 2013, 34 (24), 1783-1789.

[43] Teslovich, T.M.; Musunuru, K.; Smith, A.V.; Edmondson, A.C.; Stylianou, I.M.; Koseki, M.; Pirruccello, J.P.; Ripatti, S.; Chasman, D.I.; Willer, C.J.; Johansen, C.T.; Fouchier, S.W.; Isaacs, A.; Peloso, G.M.; Barbalic, M.; Ricketts, S.L.; Bis, J.C.; Aulchenko, Y.S.; Thorleifsson, G.; Feitosa, M.F.; Chambers, J.; Orho-Melander, M.; Melander, O.; Johnson, T.; Li, X.; Guo, X.; Li, M.; Shin Cho, Y.; Jin Go, M.; Jin Kim, Y.; Lee, J.Y.; Park, T.; Kim, K.; Sim, X.; Twee-Hee Ong, R.; Croteau-Chonka, D.C.; Lange, L.A.; Smith, J.D.; Song, K.; Hua Zhao, J.; Yuan, X.; Luan, J.; Lamina, C.; Ziegler, A.; Zhang, W.; Zee, R.Y.; Wright, A.F.; Witteman, J.C.; Wilson, J.F.; Willemsen, G.; Wichmann, H.E.; Whitfield, J.B.; Waterworth, D.M.; Wareham, N.J.; Waeber, G.; Vollenweider, P.; Voight, B.F.; Vitart, V.; Uitterlinden, A.G.; Uda, M.; Tuomilehto, J.; Thompson, J.R.; Tanaka, T.; Surakka, I.; Stringham, H.M.; Spector, T.D.; Soranzo, N.; Smit, J.H.; Sinisalo, J.; Silander, K.; Sijbrands, E.J.; Scuteri, A.; Scott, J.; Schlessinger, D.; Sanna, S.; Salomaa, V.; Saharinen, J.; Sabatti, C.; Ruokonen, A.; Rudan, I.; Rose, L.M.; Roberts, R.; Rieder, M.; Psaty, B.M.; Pramstaller, P.P.; Pichler, I.; Perola, M.; Penninx, B.W.; Pedersen, N.L.; Pattaro, C.; Parker, A.N.; Pare, G.; Oostra, B.A.; O'Donnell, C.J.; Nieminen, M.S.; Nickerson, D.A.; Montgomery, G.W.; Meitinger, T.; McPherson, R.; McCarthy, M.I.; McArdle, W.; Masson, D.; Martin, N.G.; Marroni, F.; Mangino, M.; Magnusson, P.K.; Lucas, G.; Luben, R.; Loos, R.J.; Lokki, M.L.; Lettre, G.; Langenberg, C.; Launer, L.J.; Lakatta, E.G.; Laaksonen, R.; Kyvik, K.O.; Kronenberg, F.; Konig, I.R.; Khaw, K.T.; Kaprio, J.; Kaplan, L.M.; Johansson, A.; Jarvelin, M.R.; Janssens, A.C.; Ingelsson, E.; Igl, W.; Kees Hovingh, G.; Hottenga, J.J.; Hofman, A.; Hicks, A.A.; Hengstenberg, C.; Heid, I.M.; Hayward, C.; Havulinna, A.S.; Hastie, N.D.; Harris, T.B.; Haritunians, T.; Hall, A.S.; Gyllensten, U.; Guiducci, C.; Groop, L.C.; Gonzalez, E.; Gieger, C.; Freimer, N.B.; Ferrucci, L.; Erdmann, J.; Elliott, P.; Ejebe, K.G.; Doring, A.; Dominiczak, A.F.; Demissie, S.; Deloukas, P.; de Geus, E.J.; de Faire, U.; Crawford, G.; Collins, F.S.; Chen, Y.D.; Caulfield, M.J.; Campbell, H.; Burtt, N.P.; Bonnycastle, L.L.; Boomsma, D.I.; Boekholdt, S.M.; Bergman, R.N.; Barroso, I.; Bandinelli, S.; Ballantyne, C.M.; Assimes, T.L.; Quertermous, T.; Altshuler, D.; Seielstad, M.; Wong, T.Y.; Tai, E.S.; Feranil, A.B.; Kuzawa, C.W.; Adair, L.S.; Taylor, H.A., Jr.; Borecki, I.B.; Gabriel, S.B.; Wilson, J.G.; Holm, H.; Thorsteinsdottir, U.; Gudnason, V.; Krauss, R.M.; Mohlke, K.L.; Ordovas, J.M.; Munroe, P.B.; Kooner, J.S.; Tall, A.R.; Hegele, R.A.; Kastelein, J.J.; Schadt, E.E.; Rotter, J.I.; Boerwinkle, E.; Strachan, D.P.; Mooser, V.; 
Stefansson, K.; Reilly, M.P.; Samani, N.J.; Schunkert, H.; Cupples, L.A.; Sandhu, M.S.; Ridker, P.M.; Rader, D.J.; van Duijn, C.M.; Peltonen, L.; Abecasis, G.R.; Boehnke, M.; Kathiresan, S. Biological, clinical and population relevance of 95 loci for blood lipids. Nature, 2010, 466 (7307), 707-713.

[44] Delahoy, P.J.; Magliano, D.J.; Webb, K.; Grobler, M.; Liew, D. The relationship between reduction in low-density lipoprotein cholesterol by statins and reduction in risk of cardiovascular outcomes: an updated meta-analysis. Clin Ther, 2009, 31 (2), 236-244.

[45] Baigent, C.; Blackwell, L.; Emberson, J.; Holland, L.E.; Reith, C.; Bhala, N.; Peto, R.; Barnes, E.H.; Keech, A.; Simes, J.; Collins, R. Efficacy and safety of more intensive lowering of LDL cholesterol: a metaanalysis of data from 170,000 participants in 26 randomised trials. Lancet, 2010, 376 (9753), 1670-1681.

[46] Baigent, C.; Keech, A.; Kearney, P.M.; Blackwell, L.; Buck, G.; Pollicino, C.; Kirby, A.; Sourjina, T.; Peto, R.; Collins, R.; Simes, R. Efficacy and safety of cholesterol-lowering treatment: prospective metaanalysis of data from 90,056 participants in 14 randomised trials of statins. Lancet, 2005, 366 (9493), 12671278.

[47] Cohen, J.C.; Stender, S.; Hobbs, H.H. APOC3, coronary disease, and complexities of Mendelian randomization. Cell Metab, 2014, 20 (3), 387-389.

[48] Lauridsen, B.K.; Stender, S.; Frikke-Schmidt, R.; Nordestgaard, B.G.; Tybjaerg-Hansen, A. Genetic variation in the cholesterol transporter NPC1L1, ischaemic vascular disease, and gallstone disease. Eur Heart J, 2015, 36 (25), 1601-1608.

[49] Ference, B.A.; Penumetcha, R. Reply: Genetic Variation in NPC1L1 and Risk of Gallstone Disease. J Am Coll Cardiol, 2015, 66 (9), 1086-1088.

[50] Rodriguez, S.; Gaunt, T.R.; Guo, Y.; Zheng, J.; Barnes, M.R.; Tang, W.; Danish, F.; Johnson, A.; Castillo, B.A.; Li, Y.R.; Hakonarson, H.; Buxbaum, S.G.; Palmer, T.; Tsai, M.Y.; Lange, L.A.; Ebrahim, S.; Davey Smith, G.; Lawlor, D.A.; Folsom, A.R.; Hoogeveen, R.; Reiner, A.; Keating, B.; Day, I.N. Lipids, obesity and gallbladder disease in women: insights from genetic studies using the cardiovascular gene-centric 50K SNP array. Eur J Hum Genet, 2015.

[51] Garcia-Calvo, M.; Lisnock, J.; Bull, H.G.; Hawes, B.E.; Burnett, D.A.; Braun, M.P.; Crona, J.H.; Davis, H.R., Jr.; Dean, D.C.; Detmers, P.A.; Graziano, M.P.; Hughes, M.; Macintyre, D.E.; Ogawa, A.; O'Neill K, A.; Iyer, S.P.; Shevell, D.E.; Smith, M.M.; Tang, Y.S.; Makarewicz, A.M.; Ujjainwalla, F.; Altmann, S.W.; Chapman, K.T.; Thornberry, N.A. The target of ezetimibe is Niemann-Pick C1-Like 1 (NPC1L1). Proc Natl Acad Sci U S A, 2005, 102 (23), 8132-8137.

[52] Weinglass, A.B.; Kohler, M.; Schulte, U.; Liu, J.; Nketiah, E.O.; Thomas, A.; Schmalhofer, W.; Williams, B.; Bildl, W.; McMasters, D.R.; Dai, K.; Beers, L.; McCann, M.E.; Kaczorowski, G.J.; Garcia, M.L. Extracellular loop C of NPC1L1 is important for binding to ezetimibe. Proc Natl Acad Sci U S A, 2008, 105 (32), 11140-11145.

[53] Xie, C.; Zhou, Z.S.; Li, N.; Bian, Y.; Wang, Y.J.; Wang, L.J.; Li, B.L.; Song, B.L. Ezetimibe blocks the internalization of NPC1L1 and cholesterol in mouse small intestine. J Lipid Res, 2012, 53 (10), 2092-2101.

[54] Tang, W.; Jia, L.; Ma, Y.; Xie, P.; Haywood, J.; Dawson, P.A.; Li, J.; Yu, L. Ezetimibe restores biliary cholesterol excretion in mice expressing Niemann-Pick C1-Like 1 only in liver. Biochim Biophys Acta, 2011, 1811 (9), 549-555.

[55] Hawes, B.E.; O'Neill K, A.; Yao, X.; Crona, J.H.; Davis, H.R., Jr.; Graziano, M.P.; Altmann, S.W. In vivo responsiveness to ezetimibe correlates with niemann-pick C1 like-1 (NPC1L1) binding affinity: Comparison of multiple species NPC1L1 orthologs. Mol Pharmacol, 2007, 71 (1), 19-29.

[56] Patrick, J.E.; Kosoglou, T.; Stauber, K.L.; Alton, K.B.; Maxwell, S.E.; Zhu, Y.; Statkevich, P.; lannucci, R.; Chowdhury, S.; Affrime, M.; Cayen, M.N. Disposition of the selective cholesterol absorption inhibitor ezetimibe in healthy male subjects. Drug Metab Dispos, 2002, 30 (4), 430-437.

[57] Davis, H.R., Jr.; Hoos, L.M.; Tetzloff, G.; Maguire, M.; Zhu, L.J.; Graziano, M.P.; Altmann, S.W. Deficiency of Niemann-Pick C1 Like 1 prevents atherosclerosis in ApoE-/- mice. Arterioscler Thromb Vasc Biol, 2007, 27 (4), 841-849. 
[58] Xie, P.; Zhu, H.; Jia, L.; Ma, Y.; Tang, W.; Wang, Y.; Xue, B.; Shi, H.; Yu, L. Genetic demonstration of intestinal NPC1L1 as a major determinant of hepatic cholesterol and blood atherogenic lipoprotein levels. Atherosclerosis, 2014, 237 (2), 609-617.

[59] Greenberg, M.E.; Smith, J.D.; Sehayek, E. Moderately decreased cholesterol absorption rates are associated with a large atheroprotective effect. Arterioscler Thromb Vasc Biol, 2009, 29 (11), 1745-1750.

[60] Briand, F.; Naik, S.U.; Fuki, I.; Millar, J.S.; Macphee, C.; Walker, M.; Billheimer, J.; Rothblat, G.; Rader, D.J. Both the peroxisome proliferator-activated receptor delta agonist, GW0742, and ezetimibe promote reverse cholesterol transport in mice by reducing intestinal reabsorption of HDL-derived cholesterol. Clin Trans/ Sci, 2009, 2 (2), 127-133.

[61] Xie, P.; Jia, L.; Ma, Y.; Ou, J.; Miao, H.; Wang, N.; Guo, F.; Yazdanyar, A.; Jiang, X.C.; Yu, L. Ezetimibe inhibits hepatic Niemann-Pick C1-Like 1 to facilitate macrophage reverse cholesterol transport in mice. Arterioscler Thromb Vasc Biol, 2013, 33 (5), 920-925.

[62] Uto-Kondo, H.; Ayaori, M.; Sotherden, G.M.; Nakaya, K.; Sasaki, M.; Yogo, M.; Komatsu, T.; Takiguchi, S.; Yakushiji, E.; Ogura, M.; Nishida, T.; Endo, Y.; Ikewaki, K. Ezetimibe enhances macrophage reverse cholesterol transport in hamsters: contribution of hepato-biliary pathway. Biochim Biophys Acta, 2014, 1841 (9), 1247-1255.

[63] Descamps, O.S.; De Sutter, J.; Guillaume, M.; Missault, L. Where does the interplay between cholesterol absorption and synthesis in the context of statin and/or ezetimibe treatment stand today? Atherosclerosis, 2011, 217 (2), 308-321.

[64] Dubuc, G.; Chamberland, A.; Wassef, H.; Davignon, J.; Seidah, N.G.; Bernier, L.; Prat, A. Statins upregulate PCSK9, the gene encoding the proprotein convertase neural apoptosis-regulated convertase-1 implicated in familial hypercholesterolemia. Arterioscler Thromb Vasc Biol, 2004, 24 (8), 1454-1459.

[65] Berthold, H.K.; Seidah, N.G.; Benjannet, S.; Gouni-Berthold, I. Evidence from a randomized trial that simvastatin, but not ezetimibe, upregulates circulating PCSK9 levels. PLoS One, 2013, 8 (3), e60095.

[66] Lakoski, S.G.; Xu, F.; Vega, G.L.; Grundy, S.M.; Chandalia, M.; Lam, C.; Lowe, R.S.; Stepanavage, M.E.; Musliner, T.A.; Cohen, J.C.; Hobbs, H.H. Indices of cholesterol metabolism and relative responsiveness to ezetimibe and simvastatin. J Clin Endocrinol Metab, 2010, 95 (2), 800-809.

[67] Catapano, A.L.; Reiner, Z.; De Backer, G.; Graham, I.; Taskinen, M.R.; Wiklund, O.; Agewall, S.; Alegria, E.; Chapman, M.J.; Durrington, P.; Erdine, S.; Halcox, J.; Hobbs, R.; Kjekshus, J.; Filardi, P.P.; Riccardi, G.; Storey, R.F.; Wood, D. ESC/EAS Guidelines for the management of dyslipidaemias The Task Force for the management of dyslipidaemias of the European Society of Cardiology (ESC) and the European Atherosclerosis Society (EAS). Atherosclerosis, 2011, 217 (1), 3-46.

[68] Norata, G.D.; Tibolla, G.; Catapano, A.L. Targeting PCSK9 for hypercholesterolemia. Annu Rev Pharmacol Toxicol, 2014, 54 (273-293.

[69] Norata, G.D.; Tibolla, G.; Catapano, A.L. Gene silencing approaches for the management of dyslipidaemia. Trends Pharmacol Sci, 2013, 34 (4), 198-205.

[70] Norata, G.D.; Tibolla, G.; Catapano, A.L. PCSK9 inhibition for the treatment of hypercholesterolemia: promises and emerging challenges. Vascul Pharmacol, 2014, 62 (2), 103-111.

[71] Norata, G.D.; Tibolla, G.; Catapano, A.L. Statins and skeletal muscles toxicity: from clinical trials to everyday practice. Pharmacol Res, 2014, 88 (107-113.

[72] Pirillo, A.; Catapano, A.L. Statin intolerance: diagnosis and remedies. Curr Cardiol Rep, 2015, 17 (5), 27.

[73] Mikhailidis, D.P.; Sibbring, G.C.; Ballantyne, C.M.; Davies, G.M.; Catapano, A.L. Meta-analysis of the cholesterol-lowering effect of ezetimibe added to ongoing statin therapy. Curr Med Res Opin, 2007, 23 (8), 2009-2026.

[74] Catapano, A.L.; Davidson, M.H.; Ballantyne, C.M.; Brady, W.E.; Gazzara, R.A.; Tomassini, J.E.; Tershakovec, A.M. Lipid-altering efficacy of the ezetimibe/simvastatin single tablet versus rosuvastatin in hypercholesterolemic patients. Curr Med Res Opin, 2006, 22 (10), 2041-2053. 
[75] Catapano, A.; Brady, W.E.; King, T.R.; Palmisano, J. Lipid altering-efficacy of ezetimibe coadministered with simvastatin compared with rosuvastatin: a meta-analysis of pooled data from 14 clinical trials. Curr Med Res Opin, 2005, 21 (7), 1123-1130.

[76] Morrone, D.; Weintraub, W.S.; Toth, P.P.; Hanson, M.E.; Lowe, R.S.; Lin, J.; Shah, A.K.; Tershakovec, A.M. Lipid-altering efficacy of ezetimibe plus statin and statin monotherapy and identification of factors associated with treatment response: a pooled analysis of over 21,000 subjects from 27 clinical trials. Atherosclerosis, 2012, 223 (2), 251-261.

[77] Foody, J.M.; Toth, P.P.; Tomassini, J.E.; Sajjan, S.; Ramey, D.R.; Neff, D.; Tershakovec, A.M.; Hu, H.; Tunceli, K. Changes in LDL-C levels and goal attainment associated with addition of ezetimibe to simvastatin, atorvastatin, or rosuvastatin compared with titrating statin monotherapy. Vasc Health Risk Manag, 2013, 9 (719-727.

[78] Davidson, M.H.; Voogt, J.; Luchoomun, J.; Decaris, J.; Killion, S.; Boban, D.; Glass, A.; Mohammad, H.; Lu, Y.; Villegas, D.; Neese, R.; Hellerstein, M.; Neff, D.; Musliner, T.; Tomassini, J.E.; Turner, S. Inhibition of intestinal cholesterol absorption with ezetimibe increases components of reverse cholesterol transport in humans. Atherosclerosis, 2013, 230 (2), 322-329.

[79] Sakamoto, K.; Kawamura, M.; Kohro, T.; Omura, M.; Watanabe, T.; Ashidate, K.; Horiuchi, T.; Hara, H.; Sekine, N.; Chin, R.; Tsujino, M.; Hiyoshi, T.; Tagami, M.; Tanaka, A.; Mori, Y.; Inazawa, T.; Hirano, T.; Yamazaki, T.; Shiba, T. Effect of Ezetimibe on LDL-C Lowering and Atherogenic Lipoprotein Profiles in Type 2 Diabetic Patients Poorly Controlled by Statins. PLoS One, 2015, 10 (9), e0138332.

[80] Farnier, M. Ezetimibe/statin combination therapy to treat patients with type 2 diabetes. Atheroscler Suppl, 2015, 17 (2-8.

[81] Ruscica, M.; Macchi, C.; Morlotti, B.; Sirtori, C.R.; Magni, P. Statin therapy and related risk of newonset type 2 diabetes mellitus. Eur J Intern Med, 2014, 25 (5), 401-406.

[82] Zafrir, B.; Jain, M. Lipid-lowering therapies, glucose control and incident diabetes: evidence, mechanisms and clinical implications. Cardiovasc Drugs Ther, 2014, 28 (4), 361-377.

[83] Giugliano, R.P. et al; for the IMPROVE-IT Investigators. Benefit of adding ezetimibe to statin therapy on cardiovascular outcomes and safety in patients with vs without diabetes: the IMPROVE-IT trial. Presented at ESC Congress 2015. London, England, UK. Abstract 1947.

[84] Satoh, M.; Takahashi, Y.; Tabuchi, T.; Minami, Y.; Tamada, M.; Takahashi, K.; Itoh, T.; Morino, Y.; Nakamura, M. Cellular and molecular mechanisms of statins: an update on pleiotropic effects. Clin Sci (Lond), 2015, 129 (2), 93-105.

[85] Moutzouri, E.; Liberopoulos, E.N.; Tellis, C.C.; Milionis, H.J.; Tselepis, A.D.; Elisaf, M.S. Comparison of the effect of simvastatin versus simvastatin/ezetimibe versus rosuvastatin on markers of inflammation and oxidative stress in subjects with hypercholesterolemia. Atherosclerosis, 2013, 231 (1), 8-14.

[86] Krysiak, R.; Okopien, B. The effect of ezetimibe and simvastatin on monocyte cytokine release in patients with isolated hypercholesterolemia. J Cardiovasc Pharmacol, 2011, 57 (4), 505-512.

[87] Krysiak, R.; Zmuda, W.; Okopien, B. The effect of ezetimibe, administered alone or in combination with simvastatin, on lymphocyte cytokine release in patients with elevated cholesterol levels. J Intern Med, 2011, 271 (1), 32-42.

[88] Ammirati, E.; Cianflone, D.; Vecchio, V.; Banfi, M.; Vermi, A.C.; De Metrio, M.; Grigore, L.; Pellegatta, F.; Pirillo, A.; Garlaschelli, K.; Manfredi, A.A.; Catapano, A.L.; Maseri, A.; Palini, A.G.; Norata, G.D. Effector Memory T cells Are Associated With Atherosclerosis in Humans and Animal Models. J Am Heart Assoc, 2012, 1 (1), 27-41.

[89] Catapano, A.L.; Pirillo, A.; Bonacina, F.; Norata, G.D. HDL in innate and adaptive immunity. Cardiovasc Res, 2014, 103 (3), 372-383.

[90] Grigore, L.; Raselli, S.; Garlaschelli, K.; Redaelli, L.; Norata, G.D.; Pirillo, A.; Catapano, A.L. Effect of treatment with pravastatin or ezetimibe on endothelial function in patients with moderate hypercholesterolemia. Eur J Clin Pharmacol, 2013, 69 (3), 341-346. 
[91] Norata, G.D.; Caligiuri, G.; Chavakis, T.; Matarese, G.; Netea, M.G.; Nicoletti, A.; O'Neill, L.A.; Marelli-Berg, F.M. The Cellular and Molecular Basis of Translational Immunometabolism. Immunity, 2015, $43(3), 421-434$.

[92] Camargo, L.M.; Franca, C.N.; Izar, M.C.; Bianco, H.T.; Lins, L.S.; Barbosa, S.P.; Pinheiro, L.F.; Fonseca, F.A. Effects of simvastatin/ezetimibe on microparticles, endothelial progenitor cells and platelet aggregation in subjects with coronary heart disease under antiplatelet therapy. Braz J Med Biol Res, 2014, $47(5), 432-437$.

[93] Lins, L.C.; Franca, C.N.; Fonseca, F.A.; Barbosa, S.P.; Matos, L.N.; Aguirre, A.C.; Bianco, H.T.; do Amaral, J.B.; Izar, M.C. Effects of ezetimibe on endothelial progenitor cells and microparticles in high-risk patients. Cell Biochem Biophys, 2014, 70 (1), 687-696.

[94] Kastelein, J.J.; Akdim, F.; Stroes, E.S.; Zwinderman, A.H.; Bots, M.L.; Stalenhoef, A.F.; Visseren, F.L.; Sijbrands, E.J.; Trip, M.D.; Stein, E.A.; Gaudet, D.; Duivenvoorden, R.; Veltri, E.P.; Marais, A.D.; de Groot, E. Simvastatin with or without ezetimibe in familial hypercholesterolemia. $N$ Engl J Med, 2008, 358 (14), 14311443.

[95] Villines, T.C.; Stanek, E.J.; Devine, P.J.; Turco, M.; Miller, M.; Weissman, N.J.; Griffen, L.; Taylor, A.J. The ARBITER 6-HALTS Trial (Arterial Biology for the Investigation of the Treatment Effects of Reducing Cholesterol 6-HDL and LDL Treatment Strategies in Atherosclerosis): final results and the impact of medication adherence, dose, and treatment duration. J Am Coll Cardiol, 2010, 55 (24), 2721-2726.

[96] Rossebo, A.B.; Pedersen, T.R.; Boman, K.; Brudi, P.; Chambers, J.B.; Egstrup, K.; Gerdts, E.; GohlkeBarwolf, C.; Holme, I.; Kesaniemi, Y.A.; Malbecq, W.; Nienaber, C.A.; Ray, S.; Skjaerpe, T.; Wachtell, K.; Willenheimer, R. Intensive lipid lowering with simvastatin and ezetimibe in aortic stenosis. N Engl J Med, 2008, 359 (13), 1343-1356.

[97] Gerdts, E.; Rossebo, A.B.; Pedersen, T.R.; Boman, K.; Brudi, P.; Chambers, J.B.; Egstrup, K.; GohlkeBarwolf, C.; Holme, I.; Kesaniemi, Y.A.; Malbecq, W.; Nienaber, C.; Ray, S.; Skjaerpe, T.; Wachtell, K.; Willenheimer, R. Impact of baseline severity of aortic valve stenosis on effect of intensive lipid lowering therapy (from the SEAS study). Am J Cardiol, 2010, 106 (11), 1634-1639.

[98] Howard, B.V.; Roman, M.J.; Devereux, R.B.; Fleg, J.L.; Galloway, J.M.; Henderson, J.A.; Howard, W.J.; Lee, E.T.; Mete, M.; Poolaw, B.; Ratner, R.E.; Russell, M.; Silverman, A.; Stylianou, M.; Umans, J.G.; Wang, W.; Weir, M.R.; Weissman, N.J.; Wilson, C.; Yeh, F.; Zhu, J. Effect of lower targets for blood pressure and LDL cholesterol on atherosclerosis in diabetes: the SANDS randomized trial. JAMA, 2008, 299 (14), 16781689.

[99] Fleg, J.L.; Mete, M.; Howard, B.V.; Umans, J.G.; Roman, M.J.; Ratner, R.E.; Silverman, A.; Galloway, J.M.; Henderson, J.A.; Weir, M.R.; Wilson, C.; Stylianou, M.; Howard, W.J. Effect of statins alone versus statins plus ezetimibe on carotid atherosclerosis in type 2 diabetes: the SANDS (Stop Atherosclerosis in Native Diabetics Study) trial. J Am Coll Cardiol, 2008, 52 (25), 2198-2205.

[100] Meaney, A.; Ceballos, G.; Asbun, J.; Solache, G.; Mendoza, E.; Vela, A.; Meaney, E. The VYtorin on Carotid intima-media thickness and overall arterial rigidity (VYCTOR) study. J Clin Pharmacol, 2009, 49 (7), 838-847.

[101] Bogiatzi, C.; Spence, J.D. Ezetimibe and regression of carotid atherosclerosis: importance of measuring plaque burden. Stroke, 2012, 43 (4), 1153-1155.

[102] Masuda, J.; Tanigawa, T.; Yamada, T.; Nishimura, Y.; Sasou, T.; Nakata, T.; Sawai, T.; Fujimoto, N.; Dohi, K.; Miyahara, M.; Nishikawa, M.; Nakamura, M.; Ito, M. Effect of combination therapy of ezetimibe and rosuvastatin on regression of coronary atherosclerosis in patients with coronary artery disease. Int Heart J, 2015, 56 (3), 278-285.

[103] Habara, M.; Nasu, K.; Terashima, M.; Ko, E.; Yokota, D.; Ito, T.; Kurita, T.; Teramoto, T.; Kimura, M.; Kinoshita, Y.; Tsuchikane, E.; Asakura, Y.; Matsubara, T.; Suzuki, T. Impact on optical coherence tomographic coronary findings of fluvastatin alone versus fluvastatin + ezetimibe. Am J Cardiol, 2014, 113 (4), 580-587. 
[104] Ballantyne, C.M.; Blazing, M.A.; King, T.R.; Brady, W.E.; Palmisano, J. Efficacy and safety of ezetimibe co-administered with simvastatin compared with atorvastatin in adults with hypercholesterolemia. Am J Cardiol, 2004, 93 (12), 1487-1494.

[105] Baigent, C.; Landray, M.J.; Reith, C.; Emberson, J.; Wheeler, D.C.; Tomson, C.; Wanner, C.; Krane, V.; Cass, A.; Craig, J.; Neal, B.; Jiang, L.; Hooi, L.S.; Levin, A.; Agodoa, L.; Gaziano, M.; Kasiske, B.; Walker, R.; Massy, Z.A.; Feldt-Rasmussen, B.; Krairittichai, U.; Ophascharoensuk, V.; Fellstrom, B.; Holdaas, H.; Tesar, V.; Wiecek, A.; Grobbee, D.; de Zeeuw, D.; Gronhagen-Riska, C.; Dasgupta, T.; Lewis, D.; Herrington, W.; Mafham, M.; Majoni, W.; Wallendszus, K.; Grimm, R.; Pedersen, T.; Tobert, J.; Armitage, J.; Baxter, A.; Bray, C.; Chen, Y.; Chen, Z.; Hill, M.; Knott, C.; Parish, S.; Simpson, D.; Sleight, P.; Young, A.; Collins, R. The effects of lowering LDL cholesterol with simvastatin plus ezetimibe in patients with chronic kidney disease (Study of Heart and Renal Protection): a randomised placebo-controlled trial. Lancet, 2011, 377 (9784), $2181-2192$. [106] Haynes, R.; Lewis, D.; Emberson, J.; Reith, C.; Agodoa, L.; Cass, A.; Craig, J.C.; de Zeeuw, D.; FeldtRasmussen, B.; Fellstrom, B.; Levin, A.; Wheeler, D.C.; Walker, R.; Herrington, W.G.; Baigent, C.; Landray, M.J. Effects of lowering LDL cholesterol on progression of kidney disease. J Am Soc Nephrol, 2014,25 (8), 1825-1833.

[107] Suzuki, H.; Watanabe, Y.; Kumagai, H.; Shuto, H. Comparative efficacy and adverse effects of the addition of ezetimibe to statin versus statin titration in chronic kidney disease patients. Ther Adv Cardiovasc Dis, 2013, 7 (6), 306-315.

[108] Bohula, E.A.; Giugliano, R.P.; Cannon, C.P.; Zhou, J.; Murphy, S.A.; White, J.A.; Tershakovec, A.M.; Blazing, M.A.; Braunwald, E. Achievement of Dual Low-Density Lipoprotein Cholesterol and High-Sensitivity C-Reactive Protein Targets More Frequent With the Addition of Ezetimibe to Simvastatin and Associated With Better Outcomes in IMPROVE-IT. Circulation, 2015, 132 (13), 1224-1233.

[109] Cuchel, M.; Bruckert, E.; Ginsberg, H.N.; Raal, F.J.; Santos, R.D.; Hegele, R.A.; Kuivenhoven, J.A.; Nordestgaard, B.G.; Descamps, O.S.; Steinhagen-Thiessen, E.; Tybjaerg-Hansen, A.; Watts, G.F.; Averna, M.; Boileau, C.; Boren, J.; Catapano, A.L.; Defesche, J.C.; Hovingh, G.K.; Humphries, S.E.; Kovanen, P.T.; Masana, L.; Pajukanta, P.; Parhofer, K.G.; Ray, K.K.; Stalenhoef, A.F.; Stroes, E.; Taskinen, M.R.; Wiegman, A.; Wiklund, O.; Chapman, M.J. Homozygous familial hypercholesterolaemia: new insights and guidance for clinicians to improve detection and clinical management. A position paper from the Consensus Panel on Familial Hypercholesterolaemia of the European Atherosclerosis Society. Eur Heart J, 2014, 35 (32), $2146-$ 2157.

[110] Nordestgaard, B.G.; Chapman, M.J.; Humphries, S.E.; Ginsberg, H.N.; Masana, L.; Descamps, O.S.; Wiklund, O.; Hegele, R.A.; Raal, F.J.; Defesche, J.C.; Wiegman, A.; Santos, R.D.; Watts, G.F.; Parhofer, K.G.; Hovingh, G.K.; Kovanen, P.T.; Boileau, C.; Averna, M.; Boren, J.; Bruckert, E.; Catapano, A.L.; Kuivenhoven, J.A.; Pajukanta, P.; Ray, K.; Stalenhoef, A.F.; Stroes, E.; Taskinen, M.R.; Tybjaerg-Hansen, A. Familial hypercholesterolaemia is underdiagnosed and undertreated in the general population: guidance for clinicians to prevent coronary heart disease: consensus statement of the European Atherosclerosis Society. Eur Heart J, 2013, 34 (45), 3478-3490a.

[111] Gagne, C.; Gaudet, D.; Bruckert, E. Efficacy and safety of ezetimibe coadministered with atorvastatin or simvastatin in patients with homozygous familial hypercholesterolemia. Circulation, 2002, 105 (21), 2469-2475.

[112] Pisciotta, L.; Fasano, T.; Bellocchio, A.; Bocchi, L.; Sallo, R.; Fresa, R.; Colangeli, I.; Cantafora, A.; Calandra, S.; Bertolini, S. Effect of ezetimibe coadministered with statins in genotype-confirmed heterozygous FH patients. Atherosclerosis, 2007, 194 (2), e116-122.

[113] Diamond, G.A.; Kaul, S. Simvastatin with or without ezetimibe in familial hypercholesterolemia. $N$ Engl J Med, 2008, 359 (5), 530; author reply 532.

[114] Avellone, G.; Di Garbo, V.; Guarnotta, V.; Scaglione, R.; Parrinello, G.; Purpura, L.; Torres, D.; Campisi, D. Efficacy and safety of long-term ezetimibe/simvastatin treatment in patients with familial hypercholesterolemia. Int Angiol, 2010, 29 (6), 514-524. 
[115] Drazic, T.; Sachdev, V.; Leopold, C.; Patankar, J.V.; Malnar, M.; Hecimovic, S.; Levak-Frank, S.; Habus, I.; Kratky, D. Synthesis and evaluation of novel amide amino-beta-lactam derivatives as cholesterol absorption inhibitors. Bioorg Med Chem, 2015, 23 (10), 2353-2359.

[116] Drazic, T.; Molcanov, K.; Sachdev, V.; Malnar, M.; Hecimovic, S.; Patankar, J.V.; Obrowsky, S.; LevakFrank, S.; Habus, I.; Kratky, D. Novel amino-beta-lactam derivatives as potent cholesterol absorption inhibitors. Eur J Med Chem, 2014, 87 (722-734.

[117] Arya, N.; Dwivedi, J.; Khedkar, V.M.; Coutinho, E.C.; Jain, K.S. Design, synthesis and biological evaluation of some 2-azetidinone derivatives as potential antihyperlipidemic agents. Arch Pharm (Weinheim), 2013, 346 (12), 872-881.

[118] Ballantyne, C.M.; Weiss, R.; Moccetti, T.; Vogt, A.; Eber, B.; Sosef, F.; Duffield, E. Efficacy and safety of rosuvastatin $40 \mathrm{mg}$ alone or in combination with ezetimibe in patients at high risk of cardiovascular disease (results from the EXPLORER study). Am J Cardiol, 2007, 99 (5), 673-680.

[119] Robinson, J.G.; Ballantyne, C.M.; Grundy, S.M.; Hsueh, W.A.; Parving, H.H.; Rosen, J.B.; Adewale, A.J.; Polis, A.B.; Tomassini, J.E.; Tershakovec, A.M. Lipid-altering efficacy and safety of ezetimibe/simvastatin versus atorvastatin in patients with hypercholesterolemia and the metabolic syndrome (from the VYMET study). Am J Cardiol, 2009, 103 (12), 1694-1702.

[120] Leiter, L.A.; Bays, H.; Conard, S.; Bird, S.; Rubino, J.; Hanson, M.E.; Tomassini, J.E.; Tershakovec, A.M. Efficacy and safety of ezetimibe added on to atorvastatin $(40 \mathrm{mg})$ compared with uptitration of atorvastatin (to $80 \mathrm{mg}$ ) in hypercholesterolemic patients at high risk of coronary heart disease. Am J Cardiol, 2008, 102 (11), 1495-1501.

[121] Conard, S.E.; Bays, H.E.; Leiter, L.A.; Bird, S.R.; Rubino, J.; Lowe, R.S.; Tomassini, J.E.; Tershakovec, A.M. Efficacy and safety of ezetimibe added on to atorvastatin $(20 \mathrm{mg}$ ) versus uptitration of atorvastatin (to $40 \mathrm{mg}$ ) in hypercholesterolemic patients at moderately high risk for coronary heart disease. Am J Cardiol, 2008, 102 (11), 1489-1494.

[122] Bays, H.E.; Davidson, M.H.; Massaad, R.; Flaim, D.; Lowe, R.S.; Tershakovec, A.M.; Jones-Burton, C. Safety and efficacy of ezetimibe added on to rosuvastatin 5 or $10 \mathrm{mg}$ versus up-titration of rosuvastatin in patients with hypercholesterolemia (the ACTE Study). Am J Cardiol, 2011, 108 (4), 523-530.

[123] Gagne, C.; Bays, H.E.; Weiss, S.R.; Mata, P.; Quinto, K.; Melino, M.; Cho, M.; Musliner, T.A.; Gumbiner, B. Efficacy and safety of ezetimibe added to ongoing statin therapy for treatment of patients with primary hypercholesterolemia. Am J Cardiol, 2002, 90 (10), 1084-1091.

[124] Bays, H.E.; Averna, M.; Majul, C.; Muller-Wieland, D.; De Pellegrin, A.; Giezek, H.; Lee, R.; Lowe, R.S.; Brudi, P.; Triscari, J.; Farnier, M. Efficacy and safety of ezetimibe added to atorvastatin versus atorvastatin uptitration or switching to rosuvastatin in patients with primary hypercholesterolemia. Am J Cardiol, 2013, 112 (12), 1885-1895.

[125] Abate, N.; Catapano, A.L.; Ballantyne, C.M.; Davidson, M.H.; Polis, A.; Smugar, S.S.; Tershakovec, A.M. Effect of ezetimibe/simvastatin versus atorvastatin or rosuvastatin on modifying lipid profiles in patients with diabetes, metabolic syndrome, or neither: Results of two subgroup analyses. $J$ Clin Lipidol, 2008, 2 (2), 91-105. 
Table 1. Effects of ezetimibe added to statins compared with statin monotherapy on blood lipids

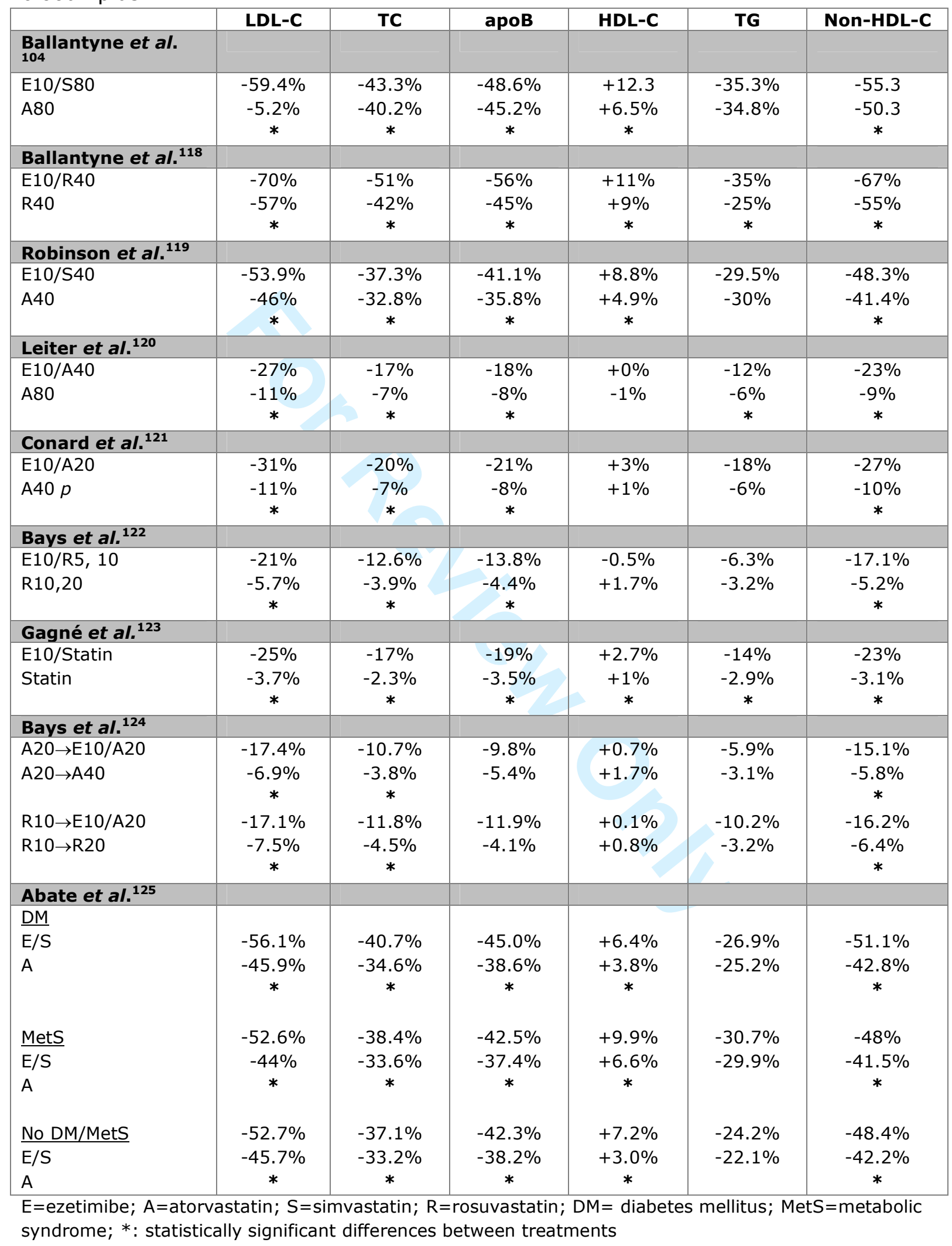


Table 2. Effects of ezetimibe+statin versus statins monotherapies on carotid atherosclerosis or major atherosclerotic events.

\begin{tabular}{|c|c|c|c|c|}
\hline & Subjects & Duration & $\begin{array}{c}\text { LDL-C } \\
\text { (\% change from } \\
\text { baseline) }\end{array}$ & Primary outcomes \\
\hline $\begin{array}{l}\text { Kastelein et al. } \\
\text { (ENHANCE) }^{94}\end{array}$ & & & & $\begin{array}{c}\text { Carotid IMT } \\
\text { (change from baseline, } \mathrm{mm} \text { ) }\end{array}$ \\
\hline $\begin{array}{l}\text { Eze } 10 \mathrm{mg} / \text { Simva } 80 \mathrm{mg} \\
\text { Simva } 80 \mathrm{mg}\end{array}$ & $\mathrm{FH}$ & $24 \mathrm{mo}$ & $\begin{array}{l}-55.6 \% \\
-39.1 \%\end{array}$ & $\begin{array}{c}+0.0111 \pm 0.0038 \\
+0.0058 \pm 0.0037 \\
P=0.29\end{array}$ \\
\hline $\begin{array}{l}\text { Villines et al. (ARBITER } \\
\text { 6-HALTS) }\end{array}$ & & & & $\begin{array}{c}\text { Carotid IMT } \\
\text { (change from baseline, } \mathrm{mm} \text { ) }\end{array}$ \\
\hline $\begin{array}{l}\text { Eze } 10 \mathrm{mg} \\
\text { Niacin } 2 \mathrm{~g}\end{array}$ & $\begin{array}{l}\text { CHD or CHD } \\
\text { equivalent on } \\
\text { stable statin } \\
\text { therapy }\end{array}$ & $14 \mathrm{mo}$ & $\begin{array}{l}-22.5 \% \\
-14 \%\end{array}$ & $\begin{array}{c}-0.0007 \pm 0.0035, N S \\
-0.0142 \pm 0.0041, P=0.001\end{array}$ \\
\hline Rossebo et al. (SEAS) ${ }^{96}$ & & & & Aortic valve events \\
\hline $\begin{array}{l}\text { Eze } 10 \mathrm{mg} / \text { Simva } 40 \mathrm{mg} \\
\text { Placebo }\end{array}$ & $\begin{array}{l}\text { Stenosis of the } \\
\text { aortic valve }\end{array}$ & $52 \mathrm{mo}$ & $\begin{array}{l}-53.8 \% \\
-3.8 \%\end{array}$ & $\begin{array}{l}32.6 \% \\
35.1 \% \\
P=0.73\end{array}$ \\
\hline $\begin{array}{l}\text { Howard et al. } \\
\text { (SANDS) }^{98}\end{array}$ & & & & Mean change CIMT $(\mathrm{mm})$ \\
\hline $\begin{array}{l}\text { Aggressive LLT } \\
\text { Standard LLT }\end{array}$ & T2DM & $36 \mathrm{mo}$ & $\begin{array}{l}-31 \% \\
+1 \%\end{array}$ & $\begin{array}{c}-0.017 \pm 0.12 \\
+0.041 \pm 0.14 \\
P<0.0001\end{array}$ \\
\hline $\begin{array}{l}\text { Aggressive Eze+Statin } \\
\text { Aggressive Statin alone }\end{array}$ & & & $\begin{array}{l}-31.1 \% \\
-32.3 \%\end{array}$ & $\begin{array}{l}-0.025 \\
-0.012 \\
P<0.0001\end{array}$ \\
\hline Masuda et al. ${ }^{102}$ & & & & $\%$ Change in plaque volume \\
\hline $\begin{array}{l}\text { Eze } 10 \mathrm{mg} / \text { Rosuva } 5 \mathrm{mg} \\
\text { Rosuva } 5 \mathrm{mg}\end{array}$ & Stable CAD & $6 \mathrm{mo}$ & $\begin{array}{l}-55.8 \% \\
-36.8 \%\end{array}$ & $\begin{array}{l}-13.2 \% \\
-3.1 \% \\
P=0.05\end{array}$ \\
\hline Habara et al..$^{103}$ & & & & $\begin{array}{c}\text { Change in the fibrous cap } \\
\text { thickness ( } \mathrm{mm})\end{array}$ \\
\hline $\begin{array}{l}\text { Eze } 10 \mathrm{mg} / \text { Fluva } 30 \mathrm{mg} \\
\text { Fluva } 30 \mathrm{mg}\end{array}$ & Angina pectoris & $9 \mathrm{mo}$ & $\begin{array}{l}-34.0 \% \\
-8.3 \% \\
P<0.001\end{array}$ & $\begin{array}{l}+0.08 \pm 0.08 \\
+0.04 \pm 0.06 \\
P<0.001\end{array}$ \\
\hline $\begin{array}{l}\text { Baigent et al. } \\
\text { (SHARP) }^{105}\end{array}$ & & & & Major atherosclerotic events \\
\hline $\begin{array}{l}\text { Eze } 10 \mathrm{mg}+\text { Simva } 20 \mathrm{mg} \\
\text { Placebo }\end{array}$ & CKD & $4.9 \mathrm{y}$ & $\begin{array}{l}-68 \% \\
-14 \%\end{array}$ & $\begin{array}{c}11.3 \% \\
13.4 \% \\
(\text { RR } 0.83, P=0.0021)\end{array}$ \\
\hline $\begin{array}{l}\text { Cannon et el. } \\
\text { (IMPROVE-IT) }^{9}\end{array}$ & & & & Primary endpoints* \\
\hline $\begin{array}{l}\text { Eze } 10 \mathrm{mg} / \text { Simva } 40 \mathrm{mg} \\
\text { Simva } 40 \mathrm{mg}\end{array}$ & ACS & $6 y$ & $\begin{array}{l}-42.8 \% \\
-25.9 \%\end{array}$ & $\begin{array}{c}32.7 \% \\
34.7 \% \\
P=0.016\end{array}$ \\
\hline
\end{tabular}

$\mathrm{FH}$ : familial hypercholesterolemia; CHD: coronary heart disease; T2DM: type 2 diabetes mellitus; CAD: coronary artery disease; CKD: chronic kidney disease; ACS: acute coronary syndrome

* Death from cardiovascular causes, major coronary event, or nonfatal stroke 


\section{Page 37 of 45 \\ Current Medicinal Chemistry}

1
2
3
4
5
6
7
8
9
1
1
1
1
1
1
1
1
1
1
2
2
2
2
2
2
2
2
2
2
3
3
3
3
3
3
3
3
3
3
4
4
4
Ezetimibe phenolic glucuronide $\sim 90 \%$

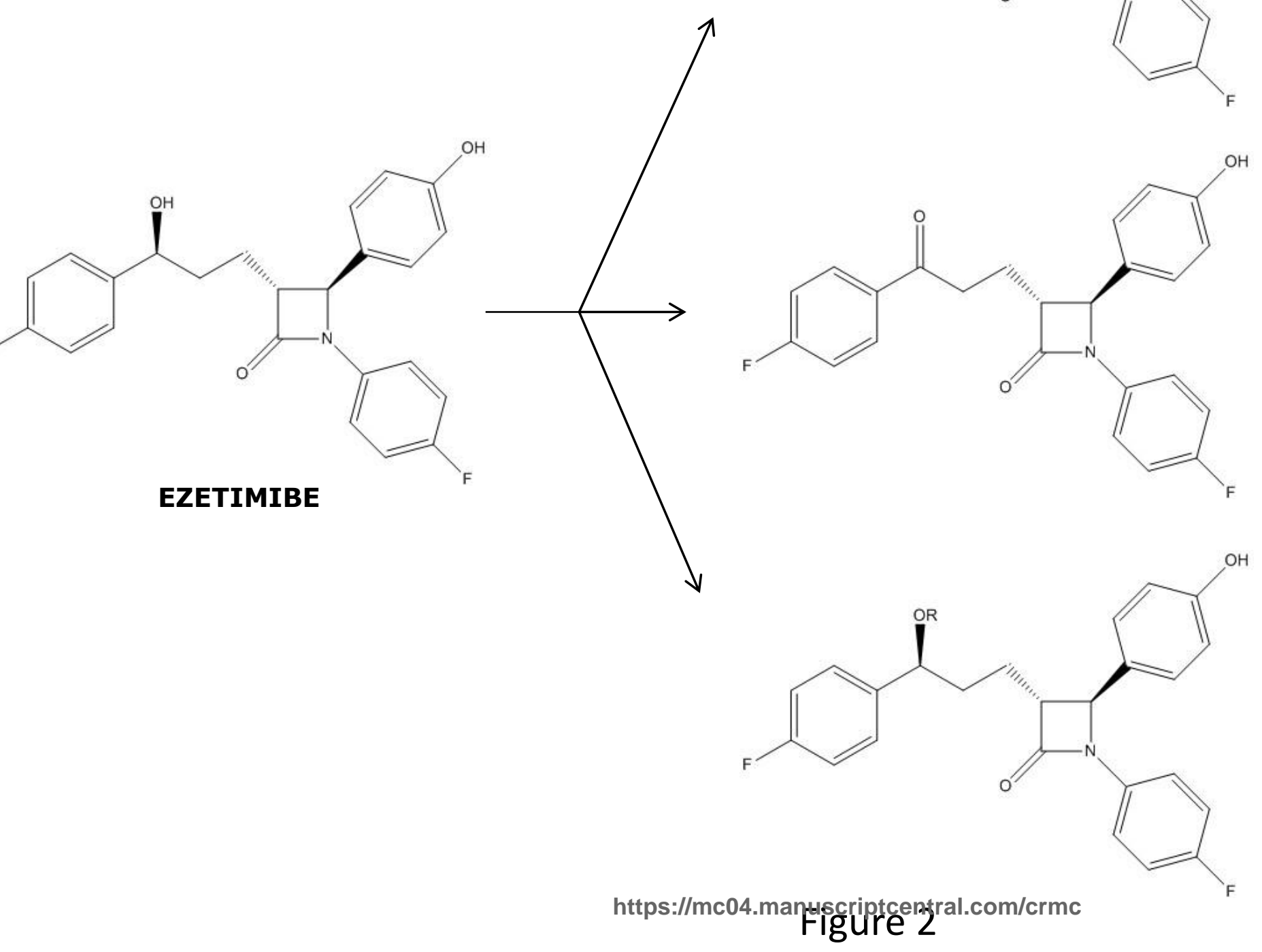

\section{Ezetimibe ketone}

Ezetimibe benzylic glucuronide $\sim 1 \%$

$$
\mathrm{R}=\mathrm{C}_{6} \mathrm{H}_{9} \mathrm{O}_{6}
$$




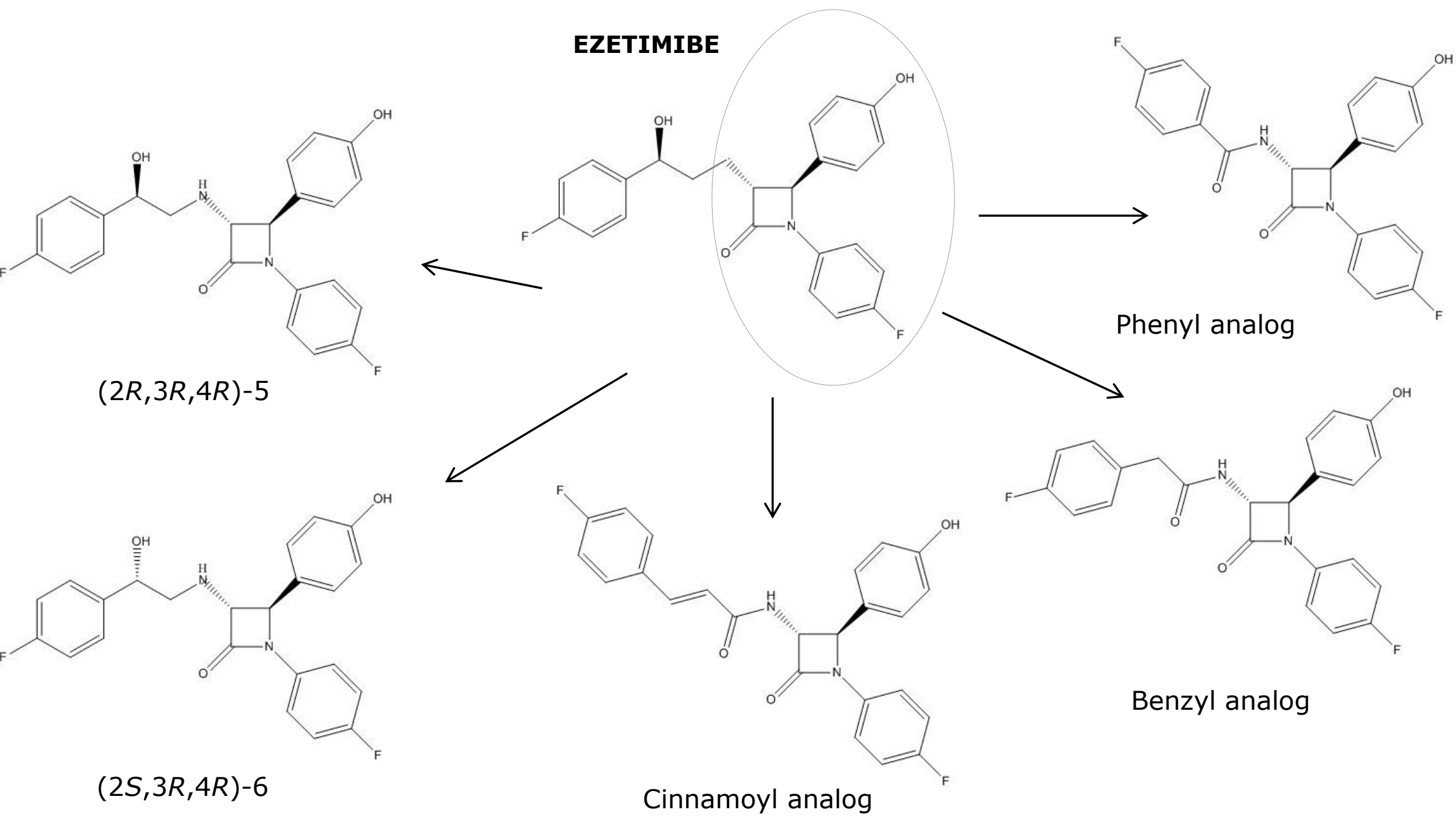

\section{Figure 3}

https://mc04.manuscriptcentral.com/crmc 


\section{Reply to comments from Reviewer: 1}

Dear Reviewer \#1, thank you for you comments.

In this revised version of the manuscript we have addressed all aspects raised by you and by the other reviewers. Concerning your specific comments, we offer the following reply:

1) Page 5, para2: Is the reference to 'high glucose' to blood levels or a cell medium? This is an important section due to the diabetes finding in IMPROVE-IT. The sense needs to be clearer i.e. (in vitro versus in vivo findings).

Sorry for the misunderstanding, these data result from "in vitro" experiments. This is now clearly stated in the text. Please see page 6, "Also high glucose levels increase the cellular uptake of cholesterol in cultured intestinal cells; this effect is due to the modulation of cholesterol transporters present in intestinal epithelial cells, being NPC1L1 and CD36 upregulated and SR-BI downregulated".

2) Page 8, para 1: The expression 'Carriers of NPCL1 .... in heterozygosis' is an unusual way of saying Carriers of a single mutant allele ...' Should be reworded.

The sentence has been reworded as follows: "Carriers of a single mutant NPC1L1 allele".

3) Page 9, para 1: 'This finding was neither confirmed ...' Better with 'not confirmed' and the rest of the sentence needs reworded.

The sentence has been reworded as suggested.

4) Page 12, para1: 'CTT' is not a trial. The reference is to the analysis conducted by the CTT collaboration.

Sorry for the mistake, the sentence has been deleted.

5) Page 12 bottom: The statements here and following relating to the lipid lowering with statin monotherapy versus statin plus ezetimibe need reworked to make clear the situation where combination therapy is superior. A high potency statin like rosuvastatin can be more effective than some combinations of statin and ezetimibe.

Your point is well taken, we have rephrased the sentence as follows (page 14):"These findings have been confirmed in a pooled analysis of over 21,000 subjects from 27 clinical trials that compared the effect of statin versus statin plus ezetimibe and showed that the combination therapy was more effective at reducing $L D L-C$ levels (treatment difference: $-15.1 \%$, $p<0.0001)$. Overall, the lipid profile was greatly improved with the combination therapy compared to similar statin doses and in most of the cases also when higher statin doses were used. Furthermore, safety profiles were comparable among the treatments".

6) Page 13, para 2: The sentence 'A greater LDL reduction ... added to a statin with high potency ...' is not easy to follow for the non-expert reader. This section needs revision to make the English clearer and the findings more specific.

Your suggestion is well taken and the sentence has been revised as follows (page 15): "The combination ezetimibe+statin was more effective at reducing $L D L-C$ levels than doubling the dose of statins $(-24.6 \%$ vs $-10.9 \%$, respectively)".

7) Page 14, para 1: Again, the sense (English and scientific) here is difficult to follow ' In other studies ... in a significantly strongest effect'.

Your suggestion is well taken and the sentence has been revised as follows (page 16): "Indeed, studies designed to evaluate the effect of ezetimibe on inflammatory markers in subjects at increased cardiovascular risk showed a decreased expression of markers of oxidative stress and inflammation. This may suggest that the beneficial effect of ezetimibe on 
inflammation could depend on the degree of plasma cholesterol reduction achieved, further supporting the correlation between plasma cholesterol and the immuno-inflammatory status".

8) Page 15, end of para 1: 'This will explain the ENHANCE results' should be 'This is a possible explanation for ...'

Your suggestion is well taken and the sentence has been amended accordingly (page 17):

"...thus perhaps explaining the findings of the ENHANCE trial".

9) Page 16, para 2: English usage needs corrected 'treatment determined a slight progression ...'. Similarly, in para 3, 'In this study 'more not only ...'.

The sentences have been reworded as follows (page 18): "....as compared with standard lipidlowering therapy that resulted in a modest carotid IMT progression"; "In this study, the addition of ezetimibe reduced was more effective in reducing not only LDL-C but also...."

10) Page 19, para 2: Sense again of 'being patients hyper responders ...'. End of para - 'massive' is not a good term in science.

Thank you for your suggestion, the paragraph was reworded as follows (page 21): "Of note, in this cohort a wide inter-individual variability response to ezetimibe was observed; indeed, ezetimibe was less effective in statin hyper-responders (who also present with a higher cholesterol synthesis and lower cholesterol absorption) and vice versa";

11) End of para - 'massive' is not a good term in science.

The sentence has been revised as follows (page 22): "...showed a considerable reduction of $L D L-C^{\prime \prime}$ 


\section{Reply to comments from Reviewer 2}

Dear Reviewer\#2, thank you for you comments.

In this revised version of the manuscript we have addressed all aspects raised by you and by the other reviewers. Concerning your specific comments, we offer the following reply:

1) In Figure 1, I suggest the authors to point out that the C-terminus of NPC1L1 is a key domain for recruitment of Numb and clathrin / AP2.

Your point is well taken, the figure has been amended accordingly.

2) Line 34, another paper should be cited: Kwon $\mathrm{HJ}$, et al., The structure of the NPC1L1 N-terminal domain in a closed conformation. Plos One, 2011

The indication that the structure of the NPC1L1 N-terminal domain is in a closed conformation was now included. Please see page 5: "The extracellular N-terminal domain of NPC1L1, that in the absence of cholesterol is in a closed conformation, directly binds cholesterol, and this interaction is essential for NPC1L1-mediated cellular cholesterol uptake".

3) Line 43, another paper should be cited: Ge $L$, et al., The cholesterol absorption inhibitor ezetimibe acts by blocking the sterol-induced internalization of NPC1L1. Cell Metabolism, 2008.

Your point is well taken the paper by Ge et al was now included in the manuscript (Reference $\left.n^{\circ} 21\right)$.

4) Page 9, line5, the NPC1L1-gallstone association should be described in a separated paragraph

Your suggestion is well taken, we now divided the two paragraphs and presented the association of NPC1L1 LOFs with cardiovascular diseases or with gallstone disease. 


\section{Reply to comments from Reviewer 3}

Dear Reviewer \#3, thank you for you comments.

In this revised version of the manuscript we have addressed all aspects raised by you and by the other reviewers. Concerning your specific comments, we offer the following reply:

\section{1) It may be better to generate a table to summarize major clinical outcomes of these trials.}

A table summarizing the major clinical outcomes of the clinical trials is now included (Table 2).

2) Most relevant papers are listed under references section, but many of them are not placed at where they should be as original studies.

Thank you for bringing this point, the references were updated accordingly. 
Dear Reviewer \#4, thank you for you comments.

In this revised version of the manuscript we have addressed all aspects raised by you and by the other reviewers. Concerning your specific comments, we offer the following reply:

\section{In the general description of the cholesterol absorption/biliary secretion pathways ABCG5/G8 should be briefly mentioned.}

Your suggestion is well taken, the description of the ABCG5/G8 pathway was now introduced. Please see page 4: "Intestinal cholesterol absorption is a complex multistep process regulated by multiple genes; among them, NPC1L1, which is involved in cholesterol uptake, and ATPbinding cassette transporters $A B C G 5$ and $A B C G 8$, that function as heterodimer and promote cholesterol efflux into the intestinal lumen for excretion. Defects in the ABCG5/ABCG8 system are linked to sitosterolemia, a condition characterized by high plasma levels of dietary sterols and premature coronary heart disease".

2. Ezetimibe increases endogenous cholesterol synthesis, which is thus far not discussed in the review. There are several spots in the text, especially where the rationale for combining this drug with statins is discussed and when selection of potential best therapy responders is mentioned, where I would suggest to touch on this issue.

Thank you for bringing this point, which is now discussed at page 13 "As the maintenance of cholesterol homeostasis is critical for several biological processes and cholesterol synthesis and absorption are inversely regulated to maintain cholesterol balance, it is not surprising that the inhibition of endogenous cholesterol absorption activates also a series of mechanistic feedbacks resulting in increased endogenous cholesterol synthesis. Thus, while statins inhibit hepatic synthesis of cholesterol and increase cholesterol absorption markers, ezetimibe negatively affects cholesterol absorption but also increases cholesterol synthesis".

\section{Given the increasing interest in PCSK9 inhibitors, the effect of ezetmibe/NPC1L1 deficiency on PCSK9 might be worth to include.}

This is also a good point and the molecular mechanisms controlling PCSK9 expression as a consequence of cholesterol homeostasis are now discussed (page 13): "These pharmacological responses may reduce the efficacy of the single drugs, but also set the stage for combining the two pharmacological approaches with the aim of limiting both cholesterol absorption and synthesis. In this context, it is worth to mention that statins cause elevation of plasma PCSK9, a proprotein convertase that promotes $L D L R$ degradation, and this effect can reduce the cholesterol-lowering efficacy of statins. However, in healthy subjects, while a 2-week treatment with simvastatin $(40 \mathrm{mg})$ resulted in the upregulation of circulating PCSK9 levels, neither ezetimibe alone nor the addition of ezetimibe to simvastatin induced an increase in PCSK9 levels. This finding could perhaps be the consequence of the limited absolute LDL-C reduction induced by ezetimibe on the top of simvastatin which may not be enough to further upregulate PCSK9 expression. In line with this, modest LDL-C lowering such as that observed with simvastatin $10 \mathrm{mg}$ does not increase PCSK9 levels".

4. Stating potential reasons for the discrepancy between LDL-C lowering (12 $\mathrm{mgdl})$ and CVD risk reduction $(-53 \%)$ would add a valuable perspective for the reader (p.8, topic: data from reference 6 ).

The observation that lifelong exposure to lower LDL-C levels even of a limited magnitude results in a greater reduction in CVD risk compared to a similar magnitude of LDL-C reduction achieved by pharmacological inhibition is true for all genes involved in lipid metabolism (including HMGCoA-Reductase LOF but also PCSK9 LOF). These clearly point to the fact that lower LDL-C since birth expose the arteries to a lower risk factor burden, while, when pharmacological intervention starts, the arteries have been exposed for decades to the risk 
factor thus requiring a more intensive lipid lowering to achieve a similar rate of vascular protection. This is now described in the main text. Please see page 9: "Extrapolation of genetic findings into pharmacology needs some caution, indeed while genetic data provides a lifelong NPC1L1 lower expression, pharmacological treatment will start later in life and be limited in time. Therefore, the benefit in terms of cardiovascular risk reduction (-53\%) as a consequence of genetically driven (NPC1L1 inactivating mutations) $L D L-C$ reduction $(-12 \mathrm{mg} / \mathrm{dL}$ ) will be much higher compared with the cardiovascular risk reduction observed in clinical trials with a similar degree of $L D L-C$ reduction. A finding which has been confirmed in all the analyses of lipid lowering genes".

5. Statins appear to increase the risk for T2DM, adding a statement on what is known with respect to ezetimibe/NPC1L1 deficiency would be helpful to provide a more complete point of view.

Your point is well taken, this aspect is now mentioned in the manuscript. Please see page 16: "Besides, it emerged that statin use may impair glucose tolerance and increase the risk of new-onset type 2 diabetes, although the benefits of cardiovascular risk reduction still largely exceeds the risk of incident diabetes. On the contrary, current data suggest that ezetimibe ameliorates glycemic control and insulin sensitivity. However, conclusive results are still lacking, as most clinical trials did not evaluate the impact of ezetimibe on glucose metabolism and commonly tested the effect of ezetimibe in combination with a statin. An analysis of the IMPROVE-IT trial suggests that type 2 diabetic patients with a recent acute coronary syndrome may benefit from the addition of ezetimibe to a statin therapy: in fact, in these subgroup of patients, ezetimibe added to a statin lowered LDL-C more than a statin alone $(43 \mathrm{mg} / \mathrm{dL}$ vs 23 $\mathrm{mg} / \mathrm{dL}$ ) and reduced the relative cardiovascular risk by $14 \%$. In non-diabetics this effect was less evident, with a $2 \%$ relative risk reduction"

6. Extending the readers view from apoB-containing lipoproteins to HDL, some mention of the impact of NPC1L1/ezetimibe on RCT should be included, since both, the hepatic (although not in rodents) and the intestinal compartment of RCT are affected by NPC1L1.This might also be pertinent to my point 4 above.

Thank you for bringing this point which is now discussed in the text. Please see page 12 : "The reduction of cholesterol absorption, promotes, as a feedback mechanism to maintain cholesterol homeostasis, the increase of reverse cholesterol transport (RCT), a process involved in the transport of cholesterol from peripheral cells back to the liver. This mechanism is common in mice genetically manipulated to present reduced cholesterol absorption, but is also observed in mice and hamsters following ezetimibe administration. These findings suggest that the inhibition of cholesterol absorption may exert an atheroprotective effects also by promoting the removal of cholesterol excess from peripheral tissues".

\section{Please carefully re-edit for punctuation, typos and use of English language.}

A careful editing was performed.

\section{Minor points:}

\section{Please cite the primary references for the statements on p.6, lines 44-53.}

The primary references were introduced. 


\section{Reviewer: 5}

Dear Reviewer \#5, thank you for you comments.

In this revised version of the manuscript we have addressed all aspects raised by you and by the other reviewers. Concerning your specific comments, we offer the following reply:

\section{Comments are necessary for the abstract:}

- Line 1: "....either endogenous production or intestinal absorption..."

- Line 6: "molecules" instead of "component"

- Line 8: no komma after "statin therapy"

- 4th line from bottom: "effects" instead of "effect"

The abstract was amended as per your suggestion. 